\title{
Flora da Bahia: Encyclia (Orchidaceae)
}

\author{
Cláudia Araújo Bastos ${ }^{1 *}$, Thiago Erir Cadete Meneguzzo ${ }^{3, a} \&$ Cássio van den Berg ${ }^{1, b}$ \\ ${ }^{1}$ Departamento de Ciências Biológicas, Universidade Estadual de Feira de Santana, Feira de Santana, Bahia, Brasil. \\ ${ }^{2}$ Instituto de Pesquisas Jardim Botânico do Rio de Janeiro, Rio de Janeiro, Rio de Janeiro, Brasil.
}

\begin{abstract}
Resumo - É apresentado o levantamento das espécies de Encyclia (Orchidaceae) ocorrentes no estado da Bahia, Brasil, como contribuição à flora do Estado. São reconhecidas 13 espécies e uma variedade de Encyclia na Bahia. É apresentada uma chave de identificação, além de descrições, ilustrações e comentários gerais para os táxons. É proposta a sinonimização de E. silvana sob E. bohnkiana e a lectotipificação de Epidendrum roseum e sua sinonimização sob Encyclia dichroma.
\end{abstract}

Palavras-chave adicionais: Brasil, orquídea, taxonomia.

\begin{abstract}
Flora of Bahia: Encyclia (Orchidaceae)) - A survey of Encyclia (Orchidaceae) species in Bahia state, Brazil, is performed as a contribution to the flora of this region. We recognized 13 species, and one variety of Encyclia from Bahia. A key for identification, descriptions, illustrations and commentaries for taxa are presented. We propose the synonymization of E. silvana under E. bohnkiana and the lectotypification of Epidendrum roseum and its synonymization under Encyclia dichroma.
\end{abstract}

Additional keywords: Brazil, orchid, taxonomy.

Orchidaceae é uma das maiores famílias de Angiospermas e está distribuída por quase todas as regiões do globo. A presença de uma pétala mediana modificada, o labelo, que serve de plataforma de pouso de polinizadores, estames e pistilo fundidos, constituindo a coluna, e grãos de pólen agrupados em polinário são características diagnósticas em Orchidaceae. Catasetum Rich. ex Kunth foi o primeiro gênero tratado para a Flora da Bahia (Bastos \& van den Berg 2012), contando com a descrição formal da família, bem como informações referentes a sua distribuição e riqueza para o Brasil e para Bahia.

\section{Encyclia Hook.}

Erva epífita, terrícola ou rupícola, ramificação simpodial. Rizoma geralmente inconspícuo. Pseudobulbos heteroblásticos, com bainhas paleáceas, piriformes, cônicos, ovoides ou esféricos. Folhas terminais ao pseudobulbo, 1-3(4), sésseis, planas ou canaliculadas, oblongas, lanceoladas, oblanceoladas ou lineares, coriáceas ou carnosas, margem inteira, ápice obtuso a agudo, base truncada. Inflorescência terminal ao pseudobulbo, geralmente maior que as folhas, em racemo simples ou duplo, sem espata, 1-25 flores, densiflora. Flores monoclinas, ressupinadas, pediceladas, frequentemente odoríferas, dialissépalas, dialipétalas; cálice com uma sépala dorsal e duas laterais, lanceoladas, oblanceoladas, oblongas, elípticas, ovais ou espatuladas, eretas, pendentes ou reflexas, carnosas ou membranáceas, margem inteira ou ondulada, ápice agudo, obtuso ou mucronado, base atenuada; a dorsal simétrica e as laterais simétricas ou assimétricas; pétalas duas espatuladas, subespatuladas

\footnotetext{
*Autora para correspondência: caubionet@yahoo.com.br; ${ }^{\mathrm{a}}$ meneguzzotec@gmail.com; ${ }^{\mathrm{b}} \mathrm{vcassio@gmail.com}$

Editor responsável: Ana Maria Giulietti

Submetido: 4 ago. 2015; aceito: 24 jan. 2016

Publicação eletrônica: 4 jul. 2016; versão final: 9 jul. 2016
}

ou lanceoladas, eretas, pendentes ou reflexas, membranáceas ou carnosas, margem inteira, suavemente serreada ou ondulada, ápice agudo, obtuso ou mucronado, base atenuada, e uma pétala livre (labelo), trilobada, istmo presente, raramente séssil; lobos laterais livres em relação ao lobo mediano, ovais, obovais, oblongos, dimidiados, ensiformes, falcados, retangulares ou triangulares, ângulo em relação ao lobo mediano (no labelo explanado) ca. $45^{\circ},<45^{\circ}$ ou $90^{\circ}$, sobrepostos ou não ao lobo mediano, margem inteira, ápice obtuso ou agudo e lobo mediano deltoide, obdeltoide, arredondado, orbicular a cordado, reniforme, espatulado, elíptico ou obovado, conduplicado, sinuoso ou plano, margem inteira, ondulada ou fimbriada, ápice emarginado a obtuso ou uncinado; calo longitudinal com sutura no centro do labelo, cimbiforme, ápice agudo, emarginado, truncado, trífido ou flabelado; coluna clavada, subclavada ou dolabriforme, ápice do clinândrio tridentado, dentes laterais arredondados a triangulares ou corniformes, ápice agudo, truncado ou premorso, dente mediano triangular, ápice agudo, frequentemente com dois braços na coluna, ovais, quadrados ou triangulares adjacentes ao estigma, de ápice obtuso ou agudo; estigma arredondado, oval a oboval ou triangular, côncavo, viscoso, com ou sem ganchos na base; rostelo curvado apicalmente; antera 1(3), caduca, incumbente; polínias 4, aos pares, lateralmente compressas, elípticas, cerosas, iguais, paralelas, amarelas, caudículo granular, viscídio ausente. Cápsula, fusiforme, lisa, verrucosa ou espiculada, 6-costada.

O gênero Encyclia inclui cerca de 150 espécies (Govaerts et al. 2013), todas neotropicais, distribuídas desde a Flórida até o norte da Argentina (Withner 1998, 2000) e nas Índias Ocidentais (van den Berg \& Carnevali 2005). Para o Brasil, Barros et al. (2013) reconheceram 54 espécies, sendo 42 endêmicas e 13 registradas na Bahia. No entanto, Bastos (2014), na 
revisão realizada para o gênero no Brasil, reconheceu 39 espécies. A partir da análise da coleção de importantes herbários brasileiros, foi constatada a ocorrência de 13 espécies e uma variedade para a Bahia.

Algumas espécies de Encyclia foram erroneamente catalogadas como ocorrentes na Bahia, decorrente da imprecisão dos dados de coleta de materiais mantidos em cultivo por diferentes orquidófilos. É o caso da $E$. xerophytica, supostamente coletada no estado (Pabst 1976), ocorrência essa que tem sido questionada. Segundo Ferreira (1996), trata-se de um material "sine loco", com origem desconhecida pelo colecionador original. Encyclia joaosaiana Campacci \& Bohnke é outra espécie que não foi encontrada nos herbários, nem mesmo o material-tipo, referido para o herbário SP. Com base na ilustração e na foto do material de $E$. joaosaiana na publicação original, essa espécie parece se tratar de um híbrido natural entre a E. alboxanthina e E. oncidioides, apresentando características intermediárias entre as duas espécies, como a forma das estruturas florais de E. alboxanthina e a coloração típica de $E$. oncidioides. As duas espécies são comumente encontradas na Chapada Diamantina, que inclui o município de Seabra, localidade do materialtipo de E. joaosaiana. Estudos moleculares e/ou morfológicos poderão testar essa hipótese, então. $\mathrm{O}$ material-tipo de E. bicalhoi também não foi encontrado no herb. SP, conforme mencionado na publicação original (Castro Neto \& Bohnke 2010). Neste caso, a descrição e a ilustração parecem indicar uma nova espécie para a Bahia. Encyclia jucuranensis Pabst \& Melo é outro nome excluído neste levantamento, pois nunca chegou a ser publicado (nome in schedula). $\mathrm{O}$ material J.J. Rereira 9, coletado na Bahia, foi identificado por Pabst no herb. HB como espécie nova, mas o exemplar estava incompleto e sua correta identificação inviabilizada. Finalmente, na coleção do herb. $\mathrm{RB}$, foi encontrado um provável registro errado para a Bahia. Trata-se da E. conchaechila, uma espécie do norte do Brasil, nativa do Alto Amazonas, nas proximidades dos rios Solimões e Negro, e que também pode ocorrer na Venezuela (Withner 2000), sendo improvável sua ocorrência na Bahia. O espécime não inclui dados precisos de coleta, tratando-se de um exemplar mantido em cultivo, com procedência duvidosa. Assim, o espécime E. Pereira s.n. (RB 69758) não foi incluído neste trabalho.

\section{Chave para as espécies}

1. Ápice do calo do labelo flabelado.

2. Margem do lobo mediano do labelo fimbriada

7. E. fimbriata

2. Margem do lobo mediano do labelo ondulada

1'. Ápice do calo do labelo truncado, agudo, bífido ou trífido.

3. Antera de cor esbranquiçada, rosada ou amarelo-clara.

4. Folhas lineares, lobos laterais do labelo com ápice agudo

5. E. bracteata

4'. Folhas oblongas, oblanceoladas ou lanceoladas, lobos laterais do labelo com ápice obtuso.

5. Flores com sépalas e pétalas amareladas, esverdeadas a amarronzadas 3. E. andrichii

5'. Flores com sépalas e pétalas rosa.

6. Labelo com lobo mediano $\leq 1 \mathrm{~cm}$ larg., istmo $\geq 0,5 \mathrm{~cm}$ compr.

6. E. dichroma

6'. Labelo com lobo mediano $\geq 1,5 \mathrm{~cm}$ larg., istmo $\leq 0,3 \mathrm{~cm}$ compr.

9. E. jenischiana

3'. Antera(s) de cor amarela intensa.

7. Lobo mediano do labelo reniforme

1. E. advena

7'. Lobo mediano do labelo orbicular, arredondado, deltoide, ovado, elíptico ou cordado.

8. Clinândrio com dentes laterais corniformes

12. E. patens

8'. Clinândrio com dentes laterais triangulares.

9. Pétalas 1-1,4 cm compr.

4. E. bohnkiana

9'. Pétalas 1,6-2,7 cm compr.

10. Erva rupícola, sépalas e pétalas reflexas

2. E. alboxanthina

10'. Erva epífita ou terrícola, sépalas e pétalas pendentes ou eretas.

11. Pseudobulbos ovoides, ca. 1,1 cm compr.

13. E. unaensis

11'. Pseudobulbos cônicos, $>5 \mathrm{~cm}$ compr.

12. Lobos laterais do labelo ovais

11. E. osmantha

$12^{\prime}$. Lobos laterais do labelo dimidiados

10. E. oncidioides

1. Encyclia advena (Rchb.f.) Porto \& Brade, Rodriguésia 1: 28. 1935.

Figuras 1 e 2A-G.

Erva epífita, 21,6-41,1 cm alt. Pseudobulbos cônicos, 5-6,2 × 1,3-2,5 cm. Folhas 2, oblanceoladas a lanceoladas, $16,6-35 \times 1,5-1,9 \mathrm{~cm}$, ápice obtuso. Inflorescência em racemo simples, 6-12 flores; pedúnculo 23,5-41 cm compr.; raque $23,3-43,8 \mathrm{~cm}$ compr. Flores com pedicelo ca. 2,6 $\times 0,4 \mathrm{~cm}$; sépalas verde-oliva, a dorsal lanceolada, $2,1-2,3 \times \mathrm{ca} .0,9 \mathrm{~cm}$, as laterais lanceoladas, $2,1-2,3 \times 0,8-0,9 \mathrm{~cm}$, eretas, carnosas, margem inteira, ápice mucronado; pétalas verde-oliva, espatuladas, $2-2,3 \times 1,2-1,5 \mathrm{~cm}$, eretas, carnosas, margem inteira, ápice obtuso, labelo com 
istmo ca. $0,2 \times 0,25 \mathrm{~cm}$, lobos laterais brancos, oblongos, ca. $1 \times 0,5-0,7 \mathrm{~cm}$, ângulo ca. $45^{\circ} \mathrm{em}$ relação ao lobo mediano (no labelo explanado), não sobrepostos ao lobo mediano, ápice obtuso, lobo mediano branco densamente tracejado de rosa, reniforme, $1-1,2 \times 1,5-1,6 \mathrm{~cm}$, conduplicado, margem inteira, ápice emarginado, calo com ápice agudo; coluna clavada, $1-1,2 \times 0,3-0,4 \mathrm{~cm}$, dentes laterais do clinândrio triangulares, ápice truncado, braços da coluna quadrados, $0,1-0,2 \times 0,1-0,2 \mathrm{~cm}$, ápice obtuso; estigma oval, com ganchos na base; antera 1, cor amarela intensa, ca. 0,3 $\times 0,3 \mathrm{~cm}$.

Endêmica do Brasil, encontrada no Nordeste e Sudeste, em áreas de Mata Atlântica, especialmente na faixa litorânea (Bastos 2014). E9: litoral. Floresce de setembro a fevereiro.

Material selecionado - Salvador, Lagoa do Abaeté, 12 ${ }^{\circ} 56^{\prime} 01^{\prime \prime}$, 38²0'59”W, fev. 1992 (fl.), D.C. Giacometti 882 (CEN).

Encyclia advena pode ser confundida com $E$. spiritusanctensis L.C.Menezes (registrada apenas para o Espírito Santo), principalmente por ambas apresentarem flores com pétalas largamente espatuladas e labelo com lobo mediano reniforme de ápice emarginado. No entanto, E. advena apresenta os lobos laterais do labelo oblongos (vs. pandurados) e o mediano menor. Além disso, E. advena apresenta labelo branco com listras róseas e E. spiritusanctensis, um labelo de fundo rosa densamente listrado de rosa mais escuro.

\section{Encyclia alboxanthina Fowlie, Orchid Digest 54:} 27. 1990.

Figuras 1 e $2 \mathrm{H}-\mathrm{O}$.

Erva rupícola, ocasionalmente terrícola em areia, 20-39, $1 \mathrm{~cm}$ alt. Pseudobulbos cônicos, 5,4-10 × 1,2-2 cm. Folhas 2-4, oblanceoladas, 15,7-29,1 × 1-2 cm, ápice obtuso a agudo. Inflorescência em racemo duplo, 9-11 flores; pedúnculo 21,7-35,5 cm compr.; raque 9,2$17,0 \mathrm{~cm}$ compr. Flores com pedicelo $2,7-3,2 \times$ ca. 0,3 cm; sépalas verde-limão, a dorsal lanceolada, 2,1-2,2 $\times$ ca. $0,9 \mathrm{~cm}$, as laterais lanceoladas, $2,1-2,2 \times 0,7-1 \mathrm{~cm}$, reflexas, carnosas, margem inteira, ápice mucronado; pétalas verde-limão, espatuladas, 2-2,2 × 1-1,3 cm, reflexas, carnosas, margem inteira, ápice mucronado, labelo com istmo $0,15-0,2 \times$ ca. $0,4 \mathrm{~cm}$, lobos laterais brancos, oblongos, 1-1,2 ×0,4-0,6 cm, ângulo ca. $90^{\circ}$ em relação ao lobo mediano (no labelo explanado), não sobrepostos ao lobo mediano, ápice obtuso, lobo mediano branco com poucos traços rosa, arredondado, ca. $0,9 \times 1,2-1,4 \mathrm{~cm}$, sinuoso, margem ondulada, ápice emarginado, calo com ápice agudo; coluna clavada, 1$1,2 \times$ ca. $0,5 \mathrm{~cm}$, dentes laterais do clinândrio triangulares, ápice agudo, braços da coluna ovais a quadrados, ca. $0,2 \times 0,2 \mathrm{~cm}$, ápice obtuso; estigma oval, com ganchos na base; antera 1, cor amarela intensa, ca. 0,3 ×0,4 cm.

Endêmica do Brasil, citada como endêmica da Chapada Diamantina (Toscano de Brito \& Cribb 2005), onde cresce exclusivamente como rupícola. No entanto, Monteiro et al. (2012) destacaram sua ocorrência na Serra de Itabaiana, no estado de Sergipe, já confirmada por diversas coletas antigas. Nesta localidade, ocorre como rupícola em afloramentos rochosos nas áreas de maior altitude (600 m s.n.m.) da serra e também como terrícola na areia branca em altitudes menores (Bastos 2014). C6, C7, D6, D7, E6, E7, F6, G6: caatinga, cerrado e campo rupestre. Floresce o ano todo.

Material selecionado - Abaíra, entre Catolés e Lagoinha, $13^{\circ} 19^{\prime}$ S, $41^{\circ} 48^{\prime} \mathrm{W}, 16$ dez. 2003 (fl.), A.A. Oliveira et. al. 266 (HUEFS); Andaraí, fazenda Volta da Pedra, $12^{\circ} 52^{\prime} \mathrm{S}, 41^{\circ} 19^{\prime} \mathrm{W}, 9$ nov. 1997 (fl.), M.L. Guedes et.al. 5512 (ALCB); Barra da Estiva, oeste da estrada Barra da Estiva-Ituaçu, $13^{\circ} 42^{\prime} \mathrm{S}, 41^{\circ} 16^{\prime} \mathrm{W}, 1300$ 1500 m s.n.m., 24 mar. 1980 (fl.), R.M. Harley 20914 (CEPEC, K, $\mathrm{SPF}$ ); Ibicoara, saída da cidade em direção à Cachoeira do Buracão,

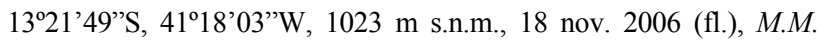
Silva-Castro et al. 1034 (HUEFS); Jacobina, Serra do Tombador, 11'5'28’S, 4042'20”'W, 915 m s.n.m., 28 abr. 2012 (fl.), T.L. Vieira

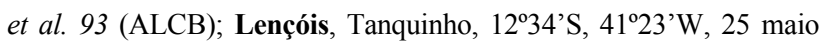
2008 (fr.), E.P. Queiroz 2776 (HRB); Morro do Chapéu, Morrão,

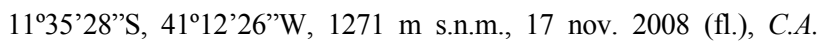
Bastos 252 (HUEFS); Mucugê, Parque Municipal de Mucugê, 12'59'S, 41'20'29”'W, 18 out. 2002 (fl.), C. Azevedo 159 (HUEFS); Palmeiras, Mucugezinho, 12 $37^{\prime} 52^{\prime \prime} \mathrm{S}, 4^{\circ} 25^{\prime} 09^{\prime \prime} \mathrm{W}, 17$ mar. 2007

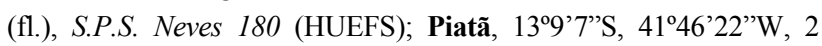
mar. 1982 (fl.), A. Seidel 1381 (HB); Pindobaçu, Serra da Paciência, 1056'36”'S, 40²4'28”'W, 1000 m s.n.m., maio 2001 (fl. e fr.), N.G. Jesus et al. 1358 (ALCB, CEPEC, HRB, HUEFS); Ruy Barbosa, Serra do Orobó, $12^{\circ} 15^{\prime} \mathrm{S}, 40^{\circ} 23^{\prime} \mathrm{W}, 11$ nov. 2004 (fl.), C. van den Berg 1432 (HUEFS); Seabra, Serra do Bebedor, a $40 \mathrm{~km}$ de Seabra,

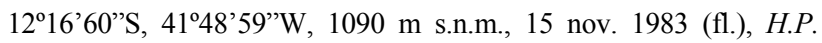
Bautista 1341 (ALCB, CEPEC, GUA, HRB, INPA, MBM, MG, RB); Senhor do Bonfim, Serra de Santana, 10²7'41's, 40¹1'22”W, 650-900 m s.n.m., 26 dez. 1984 (fl.), R.M. Silva et al. 7620 (K, SPF); Sento Sé, Minas do Mimoso, 10²0'S, 41 $20^{\circ} \mathrm{W}$, 980 m s.n.m., 6 mar. 1974 (fl.), R.M. Harley 16853 (CEPEC, HB, $\mathrm{K}, \mathrm{RB}$ ); Vitória da Conquista, fazenda Baixio do Arroz, 14'51'58"S, 4050'21'W, 1014 m s.n.m., 6 dez. 2005 (fl.), C.A.E. Leitão s.n. (VIC 31026).

Encyclia alboxanthina é similar a E. osmantha e $E$. oncidioides, ambas de ocorrência na Bahia, mas difere da primeira, que apresenta o lobo mediano deltoide e os laterais ovais, e da segunda, que possui flores acastanhadas pintalgadas de vináceo, labelo esbranquiçado com lobo mediano orbicular a cordado, ápice emarginado a uncinado e densamente listrado de vináceo.

3. Encyclia andrichii L.C.Menezes, Orchid Digest 56: 148. 1992.

Figuras 1 e $2 \mathrm{P}-\mathrm{Z}$.

Erva predominantemente epífita, 29,3-42 cm alt. Pseudobulbos cônicos, 4,6-8,1 × 1,2-2 cm. Folhas 2 ou 3, oblongas, 23,7-33,5 × 1-1,3 cm, ápice agudo. Inflorescência em racemo simples ou duplo, 8-20 flores; pedúnculo 23,1-72,5 cm compr.; raque 37,5$50,5 \mathrm{~cm}$ compr. Flores com pedicelo ca. $2-2,5 \times 0,2-$ $0,3 \mathrm{~cm}$; sépalas verde-amarronzadas, a dorsal 
lanceolada, $1,2-1,8 \times 0,4-0,6 \mathrm{~cm}, \quad$ as laterais lanceoladas, $1,2-1,8 \times 0,3-0,5 \mathrm{~cm}$, pendentes, membranáceas, margem inteira, ápice agudo; pétalas verde-amarronzadas, lanceoladas a subespatuladas, 1,1-1,7 × 0,3-0,6 cm, pendentes, membranáceas, margem suavemente serreada, ápice agudo, labelo com istmo $0,1-0,2 \times 0,2-0,3 \mathrm{~cm}$, lobos laterais amarelados com traços rosa, ovais a dimidiados, $0,6-0,8 \times 0,3-0,5$ $\mathrm{cm}$, ângulo $<45^{\circ}$ em relação ao lobo mediano (no labelo explanado), não sobrepostos ao lobo mediano, ápice obtuso, lobo mediano branco densamente tracejado de rosa, deltoide a orbicular, 0,4-0,8 $\times 0,5$ $0,9 \mathrm{~cm}$, sinuoso, margem ondulada, ápice emarginado a obtuso, calo com ápice trífido, longo; coluna clavada, 0,7-0,9 × 0,3-0,4 cm, dentes laterais do clinândrio triangulares, ápice agudo, braços da coluna ovais, 0,1$0,15 \times 0,1-0,2 \mathrm{~cm}$, ápice obtuso; estigma oval a triangular, com ganchos na base; antera 1, rosada, ca. $0,15 \times 0,2 \mathrm{~cm}$.

Endêmica do Brasil, ocorre no Nordeste, na Chapada Diamantina, Bahia, e no Sudeste, em áreas de Cerrado e Mata Atlântica (Bastos et al. 2015). D6, D7, G5, H8: mata, cerrado e área de transição entre caatinga e cerrado. Floresce de abril a dezembro.

Material selecionado - Caetité, $14^{\circ} 02^{\prime} \mathrm{S}, 42^{\circ} 30^{\prime} \mathrm{W}, 20$ nov. 2006 (fl.), M.M. Silva-Castro et al. 1076 (HUEFS); Jussari, fazenda Marineda, 15¹1'30”S, 39²9'42”W, 250 m s.n.m., jul. 1963 (fl.),

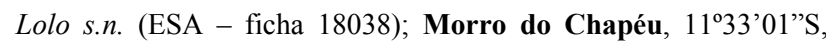
4109'22"W, 800-900 m s.n.m., 10 dez. 1997 (fl.), H. Kundergraber s.n. (holótipo SP 333602); Serrolândia, $11^{\circ} 18^{\prime} 23^{\prime \prime S}$, 40¹6'18”'W, 450 m s.n.m., 20 ago. 1980 (fl.), G.C.P. Pinto 18 (HRB).

Encycia andrichii é similar a E. seidelii Pabst (registrada apenas para Minas Gerais), que cresce sobre rocha e apresenta lobos laterais mais curtos e arredondados em relação a E. andrichii (Pabst 1976). Recentemente, foi publicada a sinonimização de $E$. kundergraeberi V.P.Castro \& Campacci, E. santanae B.P.Faria, Péres Junior \& A.D.Santana e $E$. zaslawskiana Campacci sob E. andrichii. A distribuição (Bahia, Espírito Santo e Minas Gerais), semelhanças morfológicas e os padrões de variação não permitem separá-las em unidades taxonômicas distintas (Bastos et al. 2015).

4. Encyclia bohnkiana V.P.Castro \& Campacci, Bol. CAOB 37: 91. 1999.

= Encyclia silvana V.P.Castro \& Campacci, Colet. Orquídeas Brasil. 1: 22. 2003. Tipo: BRASIL. BAHIA: Porto Seguro, arredores, 100 m s.n.m., set. 1999 (fl.), E.F. Silva s.n. (holótipo SP 363183). Syn. nov.

Figuras 3 e 4A-I.

Erva epífita, 10,6-11,5 cm alt. Pseudobulbos cônicos, 2-2,8 × 0,9-1 cm. Folha 1, oblanceolada a oblonga, $8-12 \times$ ca. $1,1 \mathrm{~cm}$, ápice obtuso a agudo. Inflorescência em racemo simples, 3 flores; pedúnculo

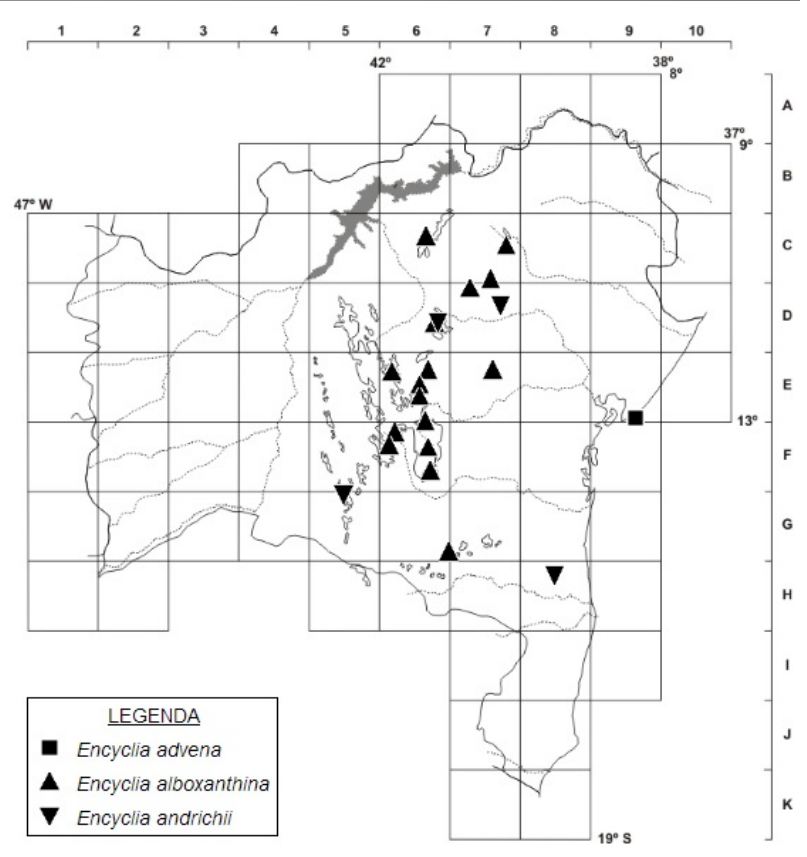

Figura 1. Mapa de distribuição geográfica na Bahia: Encyclia advena, E. alboxanthina e E. andrichii.

6,5-7,5 cm compr.; raque 2-5,5 cm compr. Flores com pedicelo ca. $1,7 \times 0,2 \mathrm{~cm}$; sépalas amarelas a esverdeadas, a dorsal oblonga a lanceolada, 1,1-1,2 $\times$ $0,3-0,5 \mathrm{~cm}$, as laterais oblongas a lanceoladas, 1,2-1,3 $\times$ ca. $0,3 \mathrm{~cm}$, pendentes, membranáceas, margem inteira, ápice agudo; pétalas amarelas a esverdeadas, subespatuladas, $1,1-1,2 \times 0,2-0,4 \mathrm{~cm}$, pendentes, membranáceas, margem inteira, ápice agudo, labelo com istmo $0,1-0,15 \times 0,2-0,3 \mathrm{~cm}$, lobos laterais amarelos a esverdeados, ensiformes, ca. 0,7 × 0,1-0,2 $\mathrm{cm}$, ângulo $<45^{\circ}$ em relação ao lobo mediano (no labelo explanado), não sobrepostos ao lobo mediano, ápice agudo, lobo mediano amarelo a esverdeado, orbicular a elíptico, 0,4-0,5 × 0,4-0,6 cm, plano, margem suavemente ondulada, ápice obtuso, calo com ápice agudo; coluna clavada, 0,6-0,9 × 0,2-0,3 cm, dentes laterais do clinândrio arredondados a triangulares, ápice agudo, braços da coluna quadrados, ca. $0,1 \times 0,15 \mathrm{~cm}$, ápice obtuso; estigma triangular, sem ganchos na base; antera 1, cor amarela intensa, ca. $0,1 \times 0,2 \mathrm{~cm}$.

Endêmica do Nordeste (Bastos 2014). D9, F8, H8, I8: Mata Atlântica. Floresce de agosto a fevereiro.

Material selecionado - Belmonte, 1551'36”S, 38 52'48”'W, 25 abr. 2010 (fl.), T.E.C. Meneguzzo 523 (HUEFS); Entre Rios, fazenda Rio do Negro, $12^{\circ} 01^{\prime} \mathrm{S}, 38^{\circ} 02^{\prime} \mathrm{W}, 28$ ago. 2009 (fl.), A.V. Popovkin 621 (HUEFS); Porto Seguro, arredores, 16²2'42”S, 3901'07'W, 100 m s.n.m., maio 1999 (f1.), E.F. Silva s.n. (holótipo de E. silvana SP 363183); Valença, Torre na BR-101, 13¹9'52'S, 39¹1'27'W, 650 m s.n.m., 30 set. 2010 (fl.), C. van den Berg 1972 (HUEFS).

Material adicional - BRASIL. ALAGOAS: Messias, Serra da Biritinga, 09²2'60'S, 3550’30”'W, fev. 1999 (fl.), E. Bohnke s.n. (holótipo SP 339145, isótipo SP 341858). 


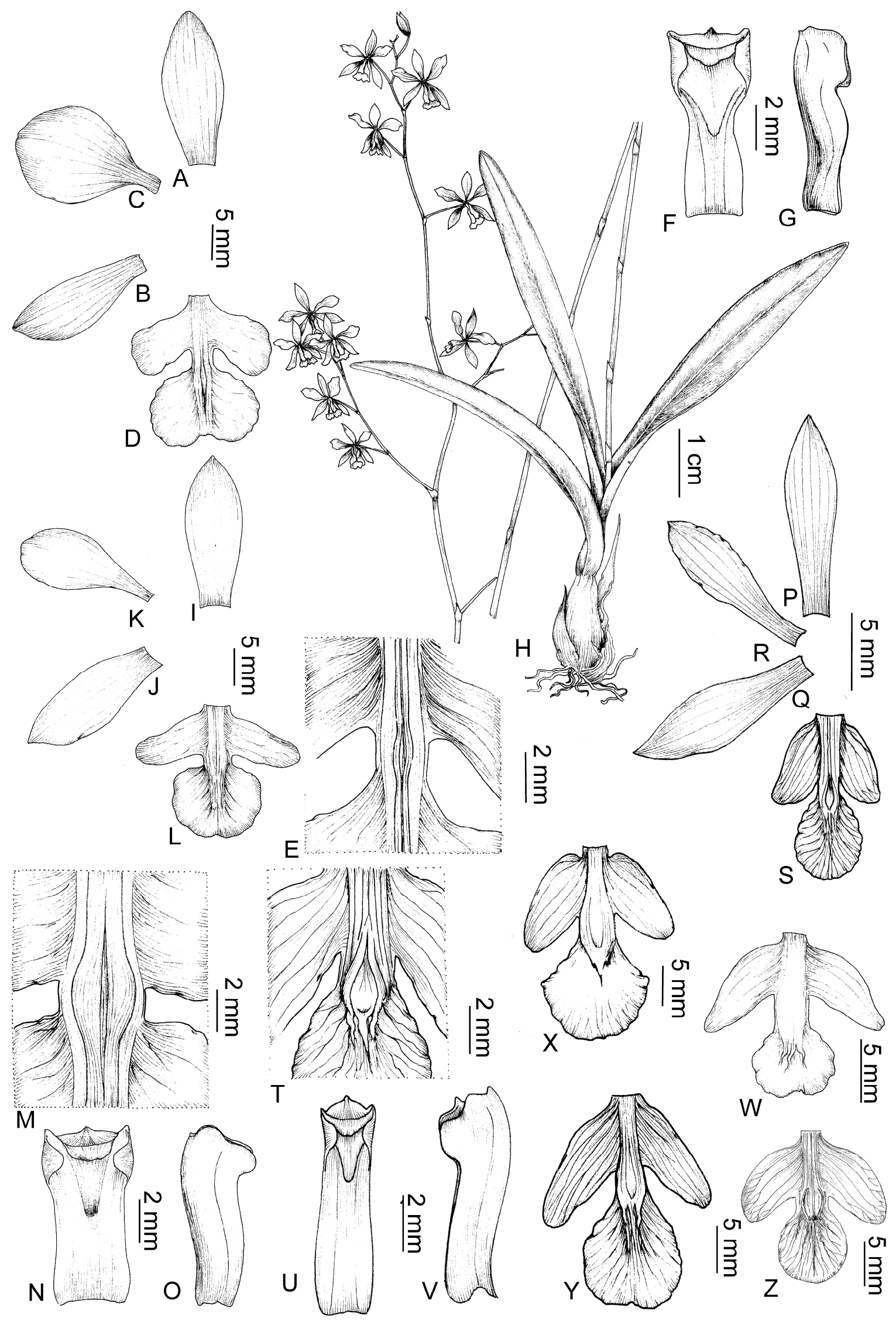

Figura 2. A-G. Encyclia advena: A- sépala dorsal; B- sépala lateral; C- pétala; D- labelo; E- detalhe do calo do labelo; F- coluna, vista ventral; G- coluna, vista lateral (Schimidt s.n. SP 52151). H-O. E. alboxanthina: H- hábito (Azevedo 159); I- sépala dorsal; J- sépala lateral; K- pétala; L- labelo; M- detalhe do calo do labelo; N- coluna, vista ventral; O- coluna, vista lateral (Bastos 89). P-Z. E. andrichii: P- sépala dorsal; Q- sépala lateral; R- pétala; S- labelo; T- detalhe do calo do labelo; U- coluna, vista ventral; V- coluna, vista lateral (Meneguzzo 473); W- variação do labelo (Bastos 176); X- variação do labelo (Bastos 289); Y- variação do labelo (Meneguzzo 567); Z- variação do labelo (Bastos 319). 
Encyclia bohnkiana costuma ser confundida com $E$. chloroleuca (Hook.) Neumann, mas esta última é exclusiva da Região Norte e é bem maior (ca. $35 \mathrm{~cm}$ alt.). Encyclia silvana é aqui tratada como sinônimo de E. bohnkiana, com base no exame dos materiais-tipo desses dois nomes. Encyclia silvana foi descrita como tendo a inflorescência com comprimento maior que as folhas e flores, que não se abrem totalmente. Entretanto, a relação dos comprimentos da inflorescência e das folhas não é um caráter taxonômico no gênero que possa justificar a separação entre duas espécies, e as flores não se abrirem totalmente em E. silvana parece indicar apenas mais um caso de cleistogamia em Encyclia, a exemplo do que ocorre entre E. patens var. patens e E. patens var. serroniana.

5. Encyclia bracteata Schltr. ex Hoehne, Album Orchid. Bras.: t. 33. 1930.

Figuras 3 e 4J-P.

Erva epífita, 17-24 cm alt. Pseudobulbos cônicos, ca. $3 \times 0,8 \mathrm{~cm}$. Folha 1 , linear, $14-21 \times 0,3-0,4 \mathrm{~cm}$, ápice agudo. Inflorescência em racemo simples, 1 flor; pedúnculo 3,5-7 cm compr.; raque ca. 2,5 cm compr. Flores com pedicelo ca. 2,2 2 0,3 cm; sépalas esverdeadas pintalgadas de castanho, a dorsal lanceolada, $1,5-1,7 \times$ ca. $0,5 \mathrm{~cm}$, as laterais lanceoladas, $1,5-1,8 \times 0,5-0,6 \mathrm{~cm}$, pendentes, carnosas, margem inteira, ápice agudo; pétalas esverdeadas sutilmente pintalgadas de castanho, espatuladas, $1,6-1,7 \times 0,5-0,6 \mathrm{~cm}$, pendentes, carnosas, margem inteira, ápice agudo, labelo com istmo ca. $0,3 \times 0,2 \mathrm{~cm}$, lobos laterais brancos, triangulares, $0,7-0,8 \times$ ca. $0,3 \mathrm{~cm}$, ângulo ca. $45^{\circ} \mathrm{em}$ relação ao lobo mediano (no labelo explanado), não sobrepostos ao lobo mediano, ápice agudo, lobo

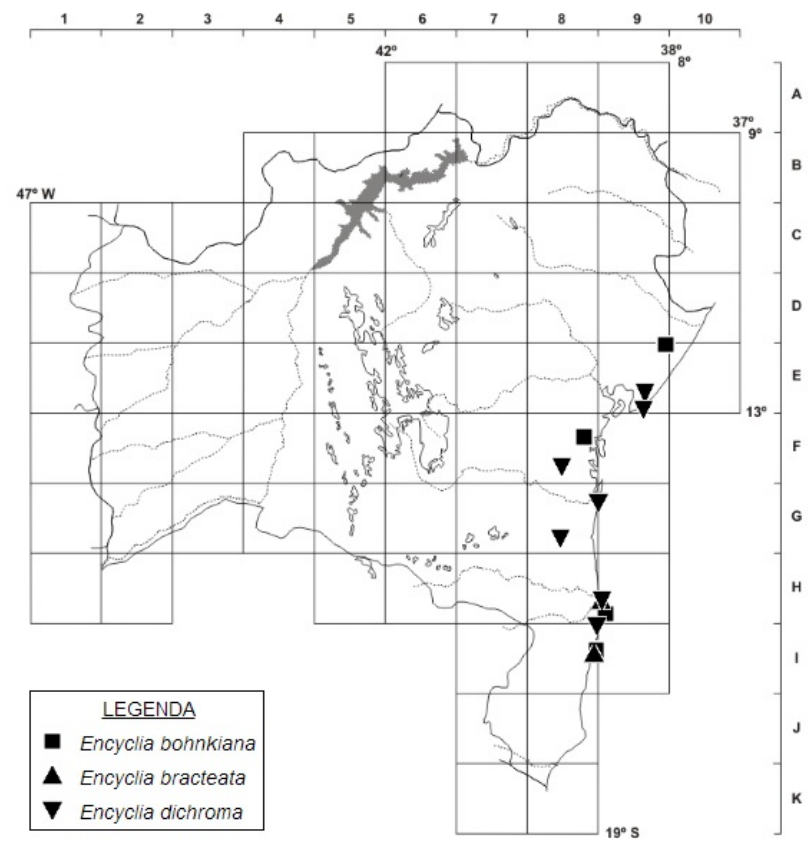

Figura 3. Mapa de distribuição geográfica na Bahia: Encyclia bohnkiana, E. bracteata e E. dichroma. mediano rosa do meio para a margem e branco até a base, obdeltoide, $0,6-0,7 \times 1,0-1,1 \mathrm{~cm}$, revoluto, margem inteira, ápice obtuso, calo com ápice agudo; coluna clavada, $0,8-0,9 \times 0,3-0,4 \mathrm{~cm}$, dentes laterais do clinândrio triangulares, ápice agudo, braços da coluna triangulares, ca. $0,1 \times 0,2-0,3 \mathrm{~cm}$, ápice agudo; estigma oval, sem ganchos na base; antera 1 [não vista], esbranquiçada.

Endêmica do Nordeste e Sudeste (Bastos 2014). H9, 19: Mata Atlântica. Floresce de novembro a maio.

Material selecionado - Canavieiras, 15\%40'31"s, 3856'50”W, 44 m s.n.m., 13 abr. 1965 (fl.), R.P. Belém \& M. Magalhães 833 (UB); Porto Seguro, estrada de Arraial d'Ajuda para Trancoso, 16² $26^{\prime}$ S, 39 $03^{\circ}$ 'W, 20 abr. 1982 (fl.), A.M. Carvalho et al. 1279 (CEPEC, SP).

Encyclia bracteata é inconfundível entre as espécies do gênero ocorrentes na Bahia. O labelo com lobo mediano obdeltoide de coloração rosa, contrastando com os lobos laterais brancos e demais partes florais esverdeadas, é bastante característico dessa espécie.

6. Encyclia dichroma (Lindl.) Schltr., Die Orchideen 1(2): 29. 1914.

= Epidendrum roseum F.Gérard, Portef. Hort. 2: 265. 1848. Material-tipo: BRASIL. BAHIA: s.1., 1847 (fl.), M. Porte s.n. (holótipo P, não localizado; lectótipo aqui designado: ilustração em aquarela em Gérard (1848, p. 266). Syn. nov.

Figuras 3 e 4Q-W.

Erva terrícola ou epífita, 16,8-21,2 cm alt. Pseudobulbos cônicos, 6,2-7,5 × 0,9-1,5 cm. Folhas 1 ou 2, oblongas a oblanceoladas, 10,6-14 × 0,9-1,2 $\mathrm{cm}$, ápice obtuso a agudo. Inflorescência em racemo simples, 6-11 flores; pedúnculo 16,2-36,6 cm compr.; raque 10,5-18,7 cm compr. Flores com pedicelo ca. $2,7 \times 0,3 \mathrm{~cm}$, sépalas rosa, a dorsal lanceolada, ca. 2,6 $\mathrm{x} 0,6 \mathrm{~cm}$, as laterais lanceoladas, ca. $2,7 \times 0,6 \mathrm{~cm}$, eretas, carnosas, margem inteira, ápice agudo; pétalas rosa, espatuladas, ca. 2,6 × 1,3 cm, eretas, carnosas, margem suavemente ondulada, ápice mucronado, labelo com istmo ca. $0,5 \times 0,2 \mathrm{~cm}$, lobos laterais rosa, retangulares, ca. $1,2 \times 0,7 \mathrm{~cm}$, ângulo $<45^{\circ}$ em relação ao lobo mediano (no labelo explanado), não sobrepostos ao lobo mediano, ápice obtuso, lobo mediano rosa com borda branca, espatulado, ca. $1 \times 1$ $\mathrm{cm}$, sinuoso, margem ondulada, ápice obtuso, calo com ápice truncado; coluna clavada, ca. 1,3 × 0,4 cm, dentes laterais do clinândrio corniformes, ápice premorso, braços da coluna ovais, ca. $0,2 \times 0,15 \mathrm{~cm}$, ápice obtuso; estigma oval, com ganchos na base; antera 1 [não vista], amarelada.

Endêmica do Nordeste (Bastos 2014). E9, F8, G8, H8: Mata Atlântica, incluindo a restinga. Floresce o ano todo.

Material selecionado - Belmonte, estrada BelmontePetrolândia, 16'1'33'S, 3900'30'”, 16 jul. 2007 (fl.), P.R.M. Almeida \& C. van den Berg 5 (HUEFS); Camaçari, Arembepe, 12² $45^{\prime}$ S, 38 $10^{\circ} \mathrm{W}, 2$ jan. 1998 (fl.), M. Carvalho 1 (HRB); 

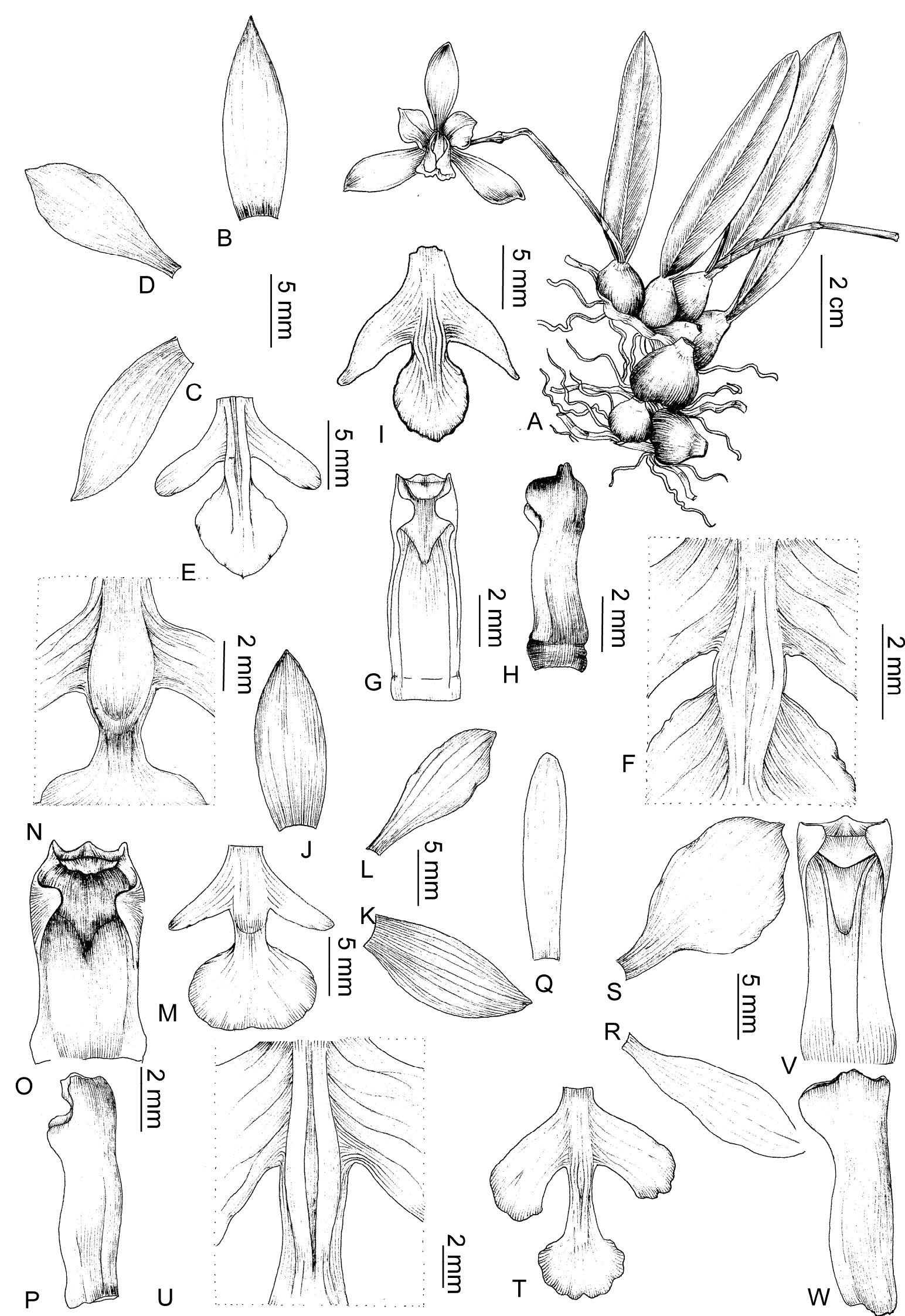

Figura 4. A-I. Encyclia bohnkiana: A- hábito (Popovkin 621); B- sépala dorsal; C- sépala lateral; D- pétala; E- labelo; F- detalhe do calo do labelo; G- coluna, vista ventral; H- coluna, vista lateral (van den Berg 1577); I- variação do labelo (Meneguzzo 523). J-P. E. bracteata: J- sépala dorsal; K- sépala lateral; L- pétala; M- labelo; N- detalhe do calo do labelo; O- coluna, vista ventral; P- coluna, vista lateral (Carvalho 1279). Q-W. E. dichroma: Q- sépala dorsal; R- sépala lateral; S- pétala; T- labelo; U- detalhe do calo do labelo; V- coluna, vista ventral; W- coluna, vista lateral (Belém 2426). 
Canavieiras, $15^{\circ} 40^{\prime} \mathrm{S}, 38^{\circ} 56^{\prime} \mathrm{W}, 28$ jun. 1966 (fl.), R.P. Belém \& R.S. Pinheiro 2426 (HB, IAN, UB); Gandu, 134' $00^{\prime}$ 'S, 39³0'00"W, maio 1962 (fl.), D. Gurgel s.n. (ESA - ficha 14977); Itacaré, estrada Ilhéus-Itacaré, 14'16'S, 3859'W, 25 jun. 1998 (fl.), L.A.M. Silva et al. 3826 (CEPEC); Salvador, Estela Mares, $12^{\circ} 56^{\prime}$ 'S, 38²1 'W, 23 fev. 1998 (fl.), C.B. Nascimento \& J. Costa 52 (HRB); Santa Luzia, conjunto Piatã Mirim, 1246’30'S, 39³1'20”'W, 28 jul. 2006 (fl.), P.R.M. Almeida \& C. van den Berg 3 (HUEFS).

Material adicional - BRASIL. PERNAMBUCO. 3 out. (fl.), Quesnel s.n. (holótipo K 293885).

Encyclia dichroma é similar a E. jenischiana, também da Bahia e que difere por apresentar o lobo mediano do labelo com cerca de $1,5 \mathrm{~cm}$ de largura e com istmo cerca de $0,3 \mathrm{~cm}$ de comprimento, além de ocorrer em ambientes não litorâneos. Almeida (2009) realizou estudos morfométricos que indicaram a separação das duas espécies, sem qualquer sobreposição de indivíduos, e os dados genéticos apontaram que são distintas mas muito proximamente relacionadas, levantando a hipótese de vicariância e especiação recentes.

Epidendrum roseum foi descrito por Gerard (1848) a partir de material do sul da Bahia. Como o holótipo não foi encontrado em $\mathrm{P}$, estamos propondo sua lectotipificação a partir da ilustração que acompanha a descrição original. O exame da ilustração e descrição de Ep. roseum mostra que suas características morfológicas correspondem perfeitamente às de $E$. dichroma, sendo aqui considerada em sua sinonímia. Withner (2000) considerou Ep. roseum sinônimo de $E$. quesneliana (que para o autor tinha como sinônimo $E$. jenischiana). Entretanto, as características florais detectadas na ilustração não correspondem às de $E$. quesneliana e nem às de E. jenischiana (considerada nesse trabalho uma espécie a parte). Além disso, na descrição original, é mencionado que a planta foi recebida dos índios Botocudos, que habitavam a região de Ilhéus, onde estão também as populações de $E$. dichroma, e não nos afloramentos rochosos do interior da Bahia, onde ocorre E. jenischiana.

7. Encyclia fimbriata C.A.Bastos, Van den Berg \& Meneguzzo, Phytotaxa 40: 27. 2012.

= Encyclia vazzoleri Castro Neto \& Vazzoler, Icon. Orchid. Brasil. 3: t. 250. 2012. nom. inval.

Figuras 5 e 6 A-I.

Erva epífita, 28,8-30,5 cm alt. Pseudobulbos cônicos, ca. $5 \times 1,1-1,4 \mathrm{~cm}$. Folhas 3, oblanceoladas a oblongas, 24,4-25 $\times 0,8-1,1 \mathrm{~cm}$, ápice agudo. Inflorescência em racemo duplo, ca. 12 flores; pedúnculo 18,3-26,4 cm compr.; raque 12,4-25 cm compr. Flores com pedicelo ca. 3 x 0,3 cm, sépalas amarelo-acastanhadas, a dorsal oval, 1,3-1,9 × 0,6-0,8 $\mathrm{cm}$, as laterais ovais, $1,5-1,8 \times 0,6-0,9 \mathrm{~cm}$, pendentes, carnosas, margem inteira, ápice mucronado; pétalas amarelo-acastanhadas, espatuladas, ca. 1,5 $\times 1 \mathrm{~cm}$, pendentes, carnosas, margem ondulada, ápice mucronado, labelo com istmo ca. $0,3 \times 0,25 \mathrm{~cm}$, lobos laterais rosa, obovais, ca. 1,3 ×0,8 cm, ângulo $<45^{\circ}$ em relação ao lobo mediano (no labelo explanado), sobrepostos ao lobo mediano, ápice obtuso, lobo mediano branco, reniforme, ca. 1,5 × $1 \mathrm{~cm}$, sinuoso, margem fimbriada, calo com ápice flabelado; coluna clavada, ca. $1 \times 0,3 \mathrm{~cm}$, dentes laterais do clinândrio corniformes, extendidos, ápice premorso, braços da coluna quadrados, ca. $0,1 \times 0,15 \mathrm{~cm}$, ápice obtuso; estigma oval, com ganchos na base; antera 1, cor amarela intensa, ca. $0,3 \times 0,2 \mathrm{~cm}$.

Conhecida inicialmente para o sul da Bahia (Bastos et al. 2012), também foi registrada para Minas Gerais (Bastos 2014). H8: mata atlântica montana. Floresce entre setembro e março.

Material examinado - Arataca, serra Peito de Moça, 1509'S, $39^{\circ} 20^{\prime} \mathrm{W}, 19$ jan. 2006 (fl.), W.W. Thomas et al. 14604 (holótipo CEPEC).

Material adicional - BRASIL. MINAS GERAIS. Santa Maria do Salto, $16^{\circ} 15^{\prime} 00^{\prime \prime}$, $40^{\circ} 07^{\prime} 00^{\prime \prime} \mathrm{W}, 900 \mathrm{~m}$ s.n.m., 24 mar. 2010 (f1.), L. Kollmann et al. 11907 (MBML).

Encylia fimbriata se diferencia das demais espécies do gênero especialmente pela presença do lobo mediano do labelo fimbriado. Tem afinidade com $E$. bragancae Ruschi, do Espírito Santo, e com E. fowliei, do sul da Bahia, onde ocorre como epífita na Mata Atlântica (Fowlie \& Duveen 1992; Barros et al. 2013; para maiores detalhes veja Bastos et al. 2012).

Encyclia vazzoleri foi publicada nove meses após a publicação de E. fimbriata, a partir de um material coletado em São José da Vitória, na Bahia, a cerca de $30 \mathrm{~km}$ do município de origem do material-tipo de $E$. fimbriata. Trata-se de um nome inválido, pois o material-tipo não foi designado, constando apenas a indicação do seu depósito no herbário SP, o que contraria o Artigo 40 do Código Internacional de Nomenclatura para algas, fungos e plantas (McNeill et al. 2012).

8. Encyclia fowliei Duveen, Orchid Digest 54: 39. 1990.

Figuras 5 e 6J-P.

Erva epífita, $27-30 \mathrm{~cm}$ alt. Pseudobulbos ovoides a esféricos, 2-3 $\times 1,5-2,2 \mathrm{~cm}$. Folhas 1 ou 2, oblanceoladas, 14-32 × 1,5-2 cm, ápice agudo. Inflorescência em racemo duplo, 1-5 flores; pedúnculo ca. $15 \mathrm{~cm}$ compr.; raque ca. $8 \mathrm{~cm}$ compr. Flores com pedicelo ca. $2 \times 0,2 \mathrm{~cm}$, sépalas amareloacastanhadas, a dorsal lanceolada a espatulada, 2,2-2,5 $\times 0,7-1,1 \mathrm{~cm}$, as laterais lanceoladas a espatuladas, $2-$ $2,3 \times 0,7-1,1 \mathrm{~cm}$, pendentes, membranáceas, margem ondulada, ápice mucronado; pétalas amareloacastanhadas, espatuladas, ca. 2,1-2,4 × 1,5-1,9 cm, pendentes, membranáceas, margem ondulada, ápice mucronado, labelo com istmo $0,2-0,3 \times \mathrm{ca}$. $0,2 \mathrm{~cm}$, lobos laterais rosa, falcados, $0,6-0,7 \times$ ca. $0,5 \mathrm{~cm}$, ângulo $<45^{\circ}$ em relação ao lobo mediano (no labelo explanado), não sobrepostos ao lobo mediano, ápice obtuso, lobo mediano rosa de ápice amarelado, reniforme, $0,5-0,6 \times$ ca. $0,8 \mathrm{~cm}$, conduplicado, 
margem suavemente ondulada, ápice obtuso, calo com ápice flabelado; coluna dolabriforme, 0,9-1,0 × 0,3$0,4 \mathrm{~cm}$, dentes laterais do clinândrio triangulares, ápice agudo, braços da coluna quadrados, ca. $0,1 \times 0,1-0,15$ $\mathrm{cm}$, ápice obtuso; estigma oval, com ganchos na base; antera 1, avermelhada, ca. $0,2 \times 0,2 \mathrm{~cm}$.

Endêmica do sul da Bahia (Campacci 2003; Barros et al. 2013). H7: Mata Atlântica. Floresce possivelmente de outubro a maio.

Material examinado - cultivo, 14 out. 2009 (fl.), C.A. Bastos \& C. van den Berg 307 (HUEFS); cultivo, 10 dez. 2010 (fl.), C.A. Bastos \& C. van den Berg 322 (HUEFS).

Encyclia fowlie é similar a E. gallopavina (Rchb.f.) Porto \& Brade (registrada apenas para o Sudeste), mas difere por essa última espécie apresentar o lobo mediano do labelo obcordado e dentes laterais do clinândrio corniformes. Não há materiais de Encyclia fowlie depositados em herbário com dados de coleta precisos. No entanto, trata-se de uma espécie que tem sido largamente cultivada entre os horticultores de orquídeas. Mesmo o material-tipo e a obra princeps não apresentam informações sobre a localidade de coleta. A obra princeps informa apenas que essa espécie ocorre próximo a riachos na costa da região central da Bahia, entre Una e Ilhéus, e o material citado por Castro Neto \& Campacci (2000) para Itororó, na Bahia, coletado por E.F. Silva s.n. (UCLA FDR 88B1) e mencionado como holótipo, não corresponde ao tipo de E. fowliei. A planta apresentada na obra princeps de $E$. bahiensis L.C.Menezes é mais um exemplar de $E$. fowliei. Entretanto, E. bahiensis é um nome inválido, pois o holótipo não foi designado.

9. Encyclia jenischiana (Rchb. f.) Porto \& Brade, Rodriguésia 1: 29. 1935.

= Encyclia ghillanyi Pabst, Bradea 2: 80. 1976.

Figuras 5 e 6Q-W.

Erva rupícola, ca. $23,8 \mathrm{~cm}$ alt. Pseudobulbos cônicos, ca. $6,6 \times 1 \mathrm{~cm}$. Folhas 2, lanceoladas, 15,3$21,5 \times 1-1,4 \mathrm{~cm}$, ápice agudo. Inflorescência em racemo simples, 4-7 flores; pedúnculo 26,2-40,5 cm compr.; raque $6,7-17,2 \mathrm{~cm}$ compr. Flores com pedicelo ca. $2,4 \times 0,2 \mathrm{~cm}$, sépalas rosa, a dorsal lanceolada, ca. 1,5 ×0,7 cm, as laterais lanceoladas, ca. 2,7 $\times 0,7 \mathrm{~cm}$, eretas, carnosas, margem inteira, ápice agudo; pétalas rosa, espatuladas, ca. 2,6 $\times 1,3 \mathrm{~cm}$, eretas, carnosas, margem inteira, ápice mucronado, labelo com istmo ca. $0,35 \times 0,3 \mathrm{~cm}$, lobos laterais rosa, oblongos, ca. $1 \times 0,6 \mathrm{~cm}$, ângulo $<45^{\circ}$ em relação ao lobo mediano (no labelo explanado), não sobrepostos ao lobo mediano, ápice obtuso, lobo mediano rosa com traços rosa mais escuro, reniforme, ca. 1,3 $\times 1,6 \mathrm{~cm}$, conduplicado, margem inteira, ápice emarginado, calo com ápice truncado; coluna clavada, ca. 1,6 ×0,5 cm, dentes laterais do clinândrio triangulares, ápice agudo, braços da coluna ovais, ca. 0,2 × 0,18 cm, ápice obtuso; estigma oval, com ganchos na base; antera 1 , amarelada.
Nesse trabalho, é considerada endêmica da Bahia. Apesar de haver registro de espécimes coletados nos estados de Minas Gerais (Brieger 17377 ESA), Rio de Janeiro ( $R$ 199926) e São Paulo (Leitão 10388 UEC), os dados de coleta são imprecisos e podem se tratar de espécimes coletados na Bahia (Bastos 2014). C8, D6, D8, E7, E8, E9, F6, F7, G6: caatinga, campo rupestre, cerrado e mata estacional. Floresce o ano todo.

Material selecionado - Barra da Estiva, Serra do Sincorá,

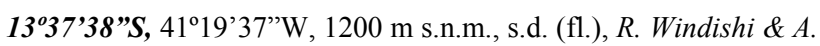
Ghillany 529 (HB); Feira de Santana, estrada Feira de SantanaIpirá, 12¹6'16”S, 37³9'03”'W, 18 ago. 2004 (fl.), A.A. Santos et al. 2450 (HUEFS); Iaçu, Morro da Garrafa, 1245'17'S, 3951'33'W, 340 m s.n.m., 9 set. 2006 (fl.), C.T. Lima et al. 51 (HUEFS); Ipirá, Estrada do Feijão, $12^{\circ} 12^{\prime}$ S, $39^{\circ} 37^{\prime} \mathrm{W}, 15$ set. 2001 (fl.), E.C. Smidt 186 (ALCB, HUEFS); Itaberaba, fazenda Bom Jardim, 12¹9'55"S, 40²7'00”'W, 472 m s.n.m., 14 jul. 2006 (bot., fl.), L.P. Queiroz \& D. Cardoso 12217 (HUEFS); Itatim, Morro das Tocas, 12 43 'S, 39²' 'W, 310-433 m s.n.m., 27 jan. 1996 (fl.), F. França et al. 1518 (HUEFS); Itiruçu, 1332'02”S, 4009'04”W, $29 \mathrm{dez}$. 2006 (fl.), P.R.M. Almeida \& C. van den Berg 1 (HUEFS); Ituiubá, Serra de Ituiubá, $10^{\circ} 43^{\prime}$ S, 39² $48^{\prime} \mathrm{W}, 700$ m s.n.m., 27 maio 1983 (fl.), G.C.P. Pinto \& H.P. Bautista 115 (HRB, MG); Jequié, estrada Jequié-Maracás, 1351'28”S, 405'00”W, 26 jan. 1980 (fl.), M.C. Vianna \& H.F. Martins 1444 (GUA); Lafaiete Coutinho, Três Morros, 1340’01'S, 40¹1'00”'W, 18 jul. 1963 (fl.), A. Oliveira de s.n. (ficha 17367 ESA); Maracás, fazenda Vale Aprazível, 13²9'12”S, 40²4'53”'W, 997 m s.n.m., 22 abr. 2002 (fl.), K.R.B. Leite et al. 252 (HUEFS); Milagres, morro São Cristóvão, 12'52'17'S, 3951'09'W, 530 m s.n.m., 13 mar. 2005 (fl.), F. França 5177 et al. (HUEFS); Ruy Barbosa, Serra do Orobó, $12^{\circ} 18^{\prime} 12^{\prime \prime}$, 40²8'43”W, 632 m s.n.m., 28 jul. 2004 (fl.), L.P. Queiroz et al. 9380 (HUEFS); Santa Teresinha, Morro do Cruzeiro, 12 ${ }^{\circ} 48^{\prime} \mathrm{S}, 39^{\circ} 32^{\prime} \mathrm{W}, 20$ dez. 2002 (fl.), C. van den Berg et al. 926 (HUEFS); Serrinha, Barra do Vento, 11\%37'29”'S,

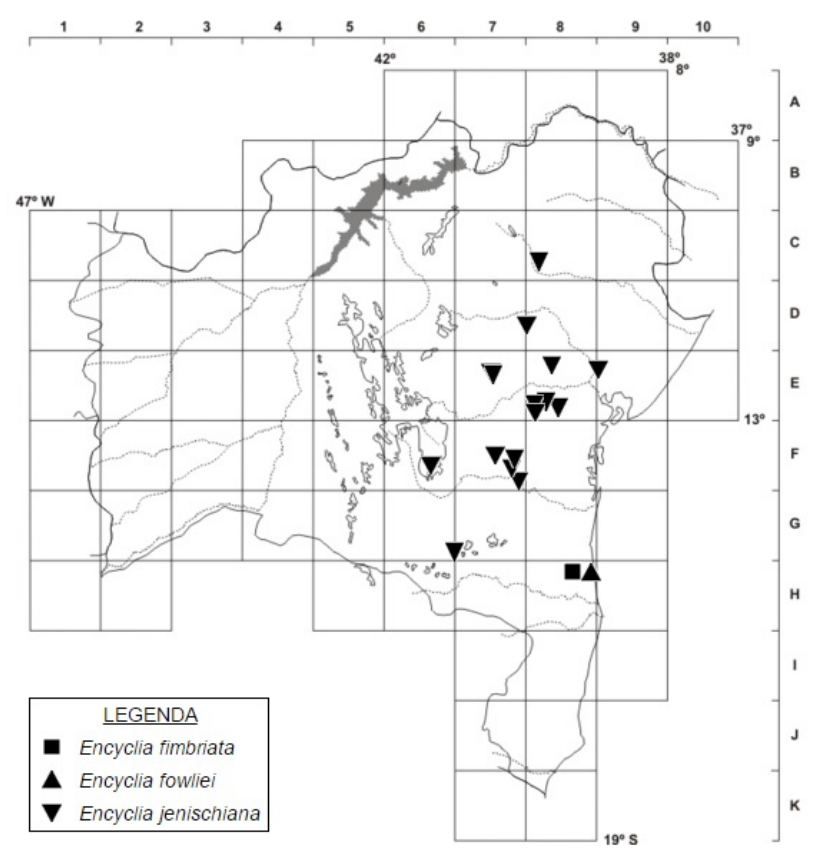

Figura 5. Mapa de distribuição geográfica na Bahia: Encyclia fimbriata, E. fowliei e E. jenischiana. 


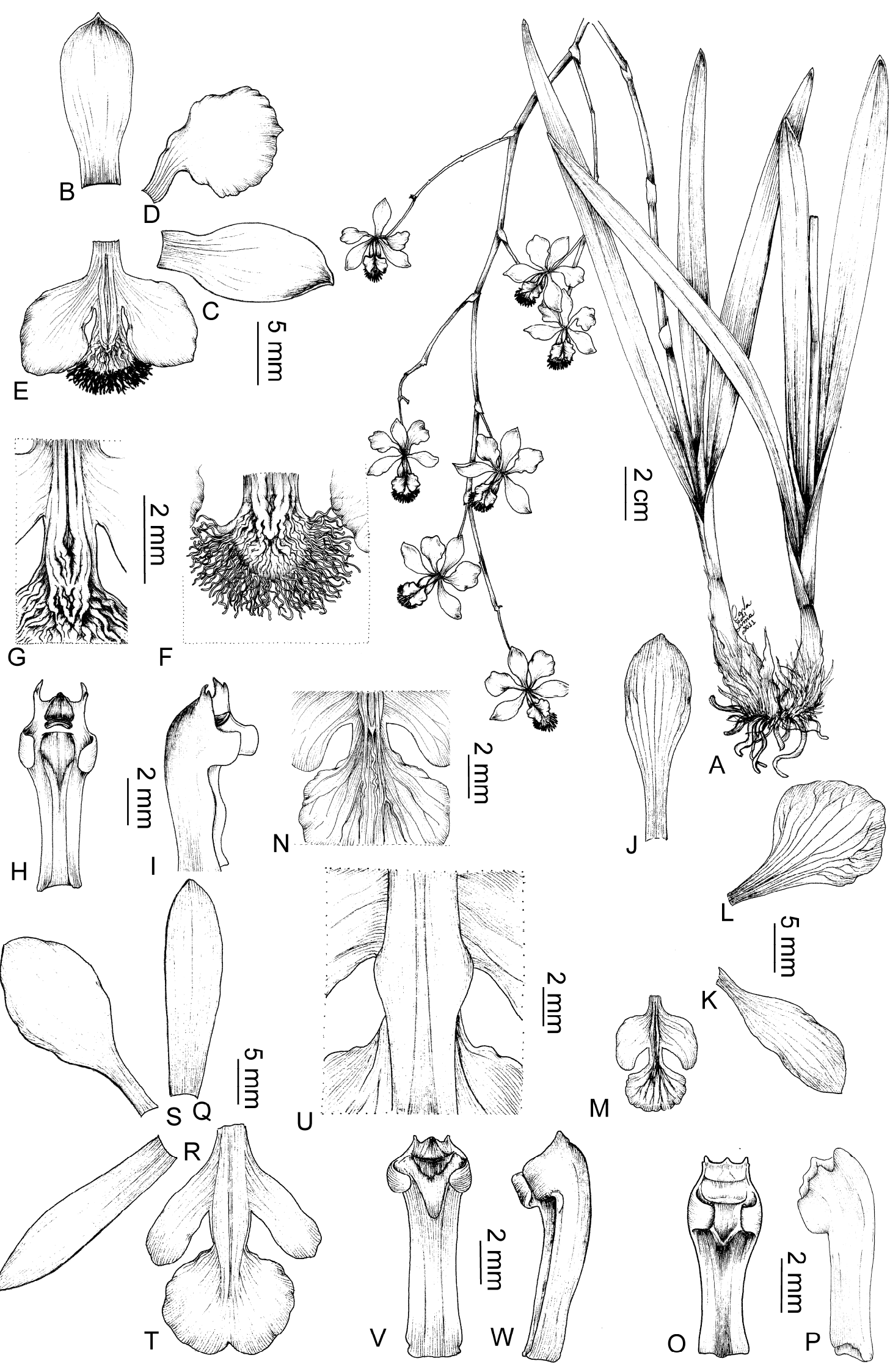

Figura 6. A-I. Encyclia fimbriata: A- hábito; B- sépala dorsal; C- sépala lateral; D- pétala; E- labelo; F- detalhe das fimbrias no lobo mediano; G- detalhe do calo do labelo; H- coluna, vista ventral; I- coluna, vista lateral (Thomas 14604). J-P. E. fowliei. J- sépala dorsal; K- sépala lateral; L- pétala; M- labelo; N- detalhe do calo do labelo; O- coluna, vista ventral; P- coluna, vista lateral (Bastos 322). Q-W. E. jenischiana. Q- sépala dorsal; R- sépala lateral; S- pétala; T- labelo; U- detalhe do calo do labelo; V- coluna, vista ventral; W- coluna, vista lateral (Almeida 4). 
3958'25”W, 20 jan. 2008 (bot., fl.), C. van den Berg 1970

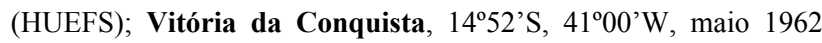
(fl.), D. Gurgel s.n. (ficha 14859 ESA).

Encyclia jenischiana é similar a E. dichroma, mas difere por caracteres florais e distribuição geográfica (veja nos comentários daquela espécie). Uma extensa lista de nomes é relacionada a E. jenischiana. Dentre seus sinônimos, destaca-se E. ghillanyi, cujo materialtipo (Ghillany s.n. HB) foi coletado na localidade de Brejeiros, a $1.200 \mathrm{~m}$ de altura (Reichenbach 1854; Pabst 1976). Segundo Toscano de Brito \& Cribb (2005), a localização precisa de Brejeiros é desconhecida, mas há relatos de que a Serra Geral da Bahia mencionada por Pabst na obra princeps com relação à localidade do espécime seja nas serras da região de Maracás (Bastos et al. 2015).

10.Encyclia oncidioides (Lindl.) Schltr., Orchideen: 210.1914.

Figuras 7 e $8 \mathrm{~A}-\mathrm{K}$.

Erva epífita ou terrícola, 40,7-46,8 cm alt. Pseudobulbos cônicos, 7,1-8,5 × 1-1,4 cm. Folhas 2 ou 3, lanceoladas, 30,7-38,5 × ca. 1,4 cm, ápice agudo. Inflorescência em racemo duplo, ca. 25 flores; pedúnculo 24,1-28,7 cm compr.; raque ca. $25 \mathrm{~cm}$ compr. Flores com pedicelo $2-2,3 \times$ ca. $0,3 \mathrm{~cm}$; sépalas amareladas manchadas de róseo ou esverdeadas, a dorsal lanceolada, 1,6-1,9 × 0,6-0,8 $\mathrm{cm}$, as laterais lanceoladas, $1,6-1,9 \times 0,6-0,7 \mathrm{~cm}$, pendentes, carnosas, margem inteira, ápice agudo a mucronado; pétalas amareladas manchadas de róseo ou esverdeadas sem manchas, espatuladas, 1,6-1,9 × 0,7$0,9 \mathrm{~cm}$, pendentes, carnosas, margem inteira, ápice obtuso a mucronado, labelo com istmo ca. $0,2 \times 0,2$ $0,3 \mathrm{~cm}$, lobos laterais amarelados, dimidiados, 0,8-0,9 $\times 0,3-0,4 \mathrm{~cm}$, ângulo em relação ao lobo mediano (no labelo explanado) ca. $90^{\circ}$, não sobrepostos ao lobo mediano, ápice obtuso, lobo mediano branco com traços róseos, orbicular a cordado, 0,7-0,8 × 0,9-1 cm, sinuoso, margem suavemente ondulada, ápice emarginado a uncinado, calo com ápice agudo; coluna clavada, ca. $1 \times 0,4-0,5 \mathrm{~cm}$, dentes laterais do clinândrio triangulares, ápice agudo, braços da coluna ovais, $0,15-0,2 \times$ ca. $0,15 \mathrm{~cm}$, ápice obtuso, estigma oval, com ganchos na base; antera 1, cor amarela intensa, 0,2-0,3 × 0,25-0,3 cm.

Ampla distribuição no Brasil (Bastos 2014). B9, D7, D8, E4, E8, E9, F6, F7, F8, G7, G8, H6, H8: caatinga, cerrado, mata estacional e restinga. Floresce o ano todo.

Material selecionado - Abaíra, estrada Abaíra-Catolés,

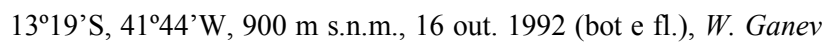
1235 (HUEFS, SPF); Andaraí, estrada para Mucugê, 1257'24"S,

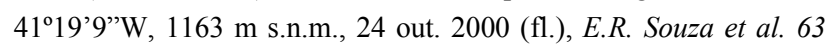
(HUEFS); Barreiras, Rio Branco, 12 $41^{\prime} 60^{\prime \prime} \mathrm{S}, 43^{\circ} 10^{\prime} 00^{\prime \prime} \mathrm{W}, 250 \mathrm{~m}$ s.n.m., jul. 1963 (fl.), Lolo s.n. (ficha 18087 ESA); Belmonte, Pratigi, 1551'36”S, 3852'48'W, s.d. (fl.), C. van den Berg 2157 (HUEFS); Cairu, Garapuá, 13²9'13”S, 3902’37’W, 14 dez. 2004 (fl.), D. Rigueira s.n. (ALCB 67949, MBM 305942); Camaçari, Guarajuba, 12³9'S, 385'W, 2 nov. 1983 (fl.), C.B.A. Bohrer 1 (HRB); Catolés, estrada Catolés-Abaíra, 13¹6'60"S, 41 ${ }^{\circ} 50$ '59”'W, 900 m s.n.m., 16 out. 1992 (fl.), W. Ganev 1235 (HUEFS, K); Conceição do Coité, Serra do Mucambo,

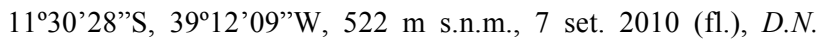
Carvalho 11 (HUEFS); Cruz das Almas, 12\%40'13"S, 3906'06”', 207 m s.n.m., 20 jan. 1956 (fl.), E.P. Heringer 5073 (UB); Entre Rios, fazenda Rio do Negro, $12^{\circ} 01^{\prime} 04^{\prime \prime} \mathrm{S}$, 38 02'55'W, 10 fev. 2009 (fr.), A.V. Popovkin 504 (HUEFS); Ilhéus, $14^{\circ} 47^{\prime} 50^{\prime} \mathrm{S}, 39^{\circ} 02^{\prime} 07^{\prime \prime} \mathrm{W}, 16$ m s.n.m., 15 fev. 1966 (fl.), R.P. Belém 2033 (UB); Ipirá, fazenda Recreio, $12^{\circ} 22^{\prime} \mathrm{S}, 39^{\circ} 41^{\prime} \mathrm{W}$, 22 nov. 1986 (fl.), L.P. Queiroz 1387 (HUEFS); Itacaré, fazenda Monte Alegre, $14^{\circ} 19^{\prime} \mathrm{S}, 39^{\circ} 15^{\prime} \mathrm{W}, 12$ jan. 2003 (fl.), J.G. Jardim 4138 (HUEFS); Ituberá, estrada para a praia de Pratigi, 1343'56"S, 3908'56"W, 15 out. 1998 (fl.), G. Hatschbach et al. 68552 (MBM, MG); Jequié, 1353'27'S, 4007'20”W, $671 \mathrm{~m}$ s.n.m., 13 abr. 2007 (fl.), L.P. Queiroz 12994 (HUEFS); Lafaiete Coutinho, Três Morros, $13^{\circ} 40^{\prime} 01^{\prime \prime}$, $40^{\circ} 11^{\prime} 00^{\prime}$ W, 750 m s.n.m., 18 jul. 1963 (fl.), Lolo s.n. (ficha 17375 ESA); Maraú, estrada Saquaíra-Campinhos, 1359'18”S, 3857’08”W, 6 set. 1999 (fl.), A. M. Carvalho et al. 6791 (CEPEC); Mata de São João, Costa do Sauípe, 12³1'50’'S, 38¹7'57’W, 17 out. 2003 (fl.), D.M. Loureiro et al. 750 (ALCB); Morro do Chapéu, arredores da

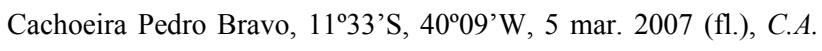
Bastos 156 (HUEFS); Mucugê, Reserva do Projeto Sempre-Viva, 1259'30"S, 41²0'30"W, 955 m s.n.m., 24 out. 2000 (fl.), E.R. Souza et al. 88 (HUEFS); Paulo Afonso, Estação Ecológica Raso da Catarina, 0948'32'S, 3829'32'W, 1 dez. 2005 (fl.), A.O. Moraes et al. 100 (HUEFS); Rio de Contas, estrada Rio de Contas-Marcolino Moura, 13³6'16"S, 41²4'52'W, 1055 m s.n.m., 18 jan. 2000 (fl.), $F$. Juchum et al. 69 (CEPEC); Salvador, Dunas de Armação, 1258'60"S, 38³0'59”'W, 1959 (fl.), L.L. Costa 407 (ALCB); Serrinha, Barra do Vento, $15^{\circ} 11^{\prime} \mathrm{S}, 41^{\circ} 35^{\prime} \mathrm{W}, 17 \mathrm{dez} .2004$ (fl.), $C$. van den Berg 1434 (HUEFS); Una, Reserva Biológica de Una, $15^{\circ} 10^{\prime} \mathrm{S}, 39^{\circ} 04^{\prime} \mathrm{W}, 40-50 \mathrm{~m}$ s.n.m., 28 out. 2001 (fl.), W.W. Thomas et al. 12651 (CEPEC); Vitória da Conquista, 1451'01'S, 4050'59’'W, 21 nov. 1978 (fl.), S.A. Mori et al. 11296 (CEPEC, HB).

Dentre as principais características que auxiliam na identificação de E. oncidioides, estão o labelo com lobo mediano orbicular a cordado, de ápice emarginado a uncinado, e flores amareladas com manchas róseas ou esverdeadas sem manchas, além do labelo branco com listras róseas. As populações de E. oncidioides do interior e do litoral da Bahia apresentam variação na morfologia e coloração das flores. Os espécimes coletados no Pratigi, no município de Belmonte, apresentam flores mais pálidas e esverdeadas, enquanto os espécimes da Chapada Diamantina apresentam sépalas e pétalas mais amareladas e pintalgadas de rosa e o lobo mediano do labelo densamente listrado de rosa.
11.Encyclia osmantha (Barb.Rodr.) Schltr., Orchideen: 210. 1914.
Figuras 7 e 8L-R.
Erva epífita, eventualmente rupícola, $15-56 \mathrm{~cm}$ alt. Pseudobulbos cônicos, 5-11 × 1-1,5 cm. Folhas 2 ou 
3, oblanceoladas, $12-45 \times 1-2,5 \mathrm{~cm}$, ápice obtuso. Inflorescência em racemo duplo, 7-25 flores; pedúnculo $26-50 \mathrm{~cm}$ compr.; raque $20-40 \mathrm{~cm}$ compr. Flores com pedicelo $2,4-2,9 \times 0,3-0,4 \mathrm{~cm}$, sépalas verde-acastanhadas, a dorsal lanceolada, $2-2,5 \times$ ca. $0,7 \mathrm{~cm}$, as laterais lanceoladas, $1,9-2,5 \times 0,6-0,8 \mathrm{~cm}$, pendentes, carnosas, margem inteira, ápice agudo; pétalas verde-acastanhadas, espatuladas, $1,8-2,6 \times 0,8$ $2,0 \mathrm{~cm}$, pendentes, carnosas, margem inteira, ápice agudo, labelo com istmo $0,15-0,2 \times 0,3-0,4 \mathrm{~cm}$, lobos laterais amarelados, ovais, $0,7-1,2 \times 0,5-0,6 \mathrm{~cm}$, ângulo $<45^{\circ}$ em relação ao lobo mediano (no labelo explanado), às vezes sobrepostos ao lobo mediano, ápice obtuso, lobo mediano branco com poucos traços róseos, deltoide, 0,9-1,2 × 1,2-1,8 cm, plano, margem suavemente ondulada, ápice emarginado, calo com ápice agudo; coluna clavada, $1-1,2 \times 0,4-0,5 \mathrm{~cm}$, dentes laterais do clinândrio triangulares, ápice agudo, braços da coluna quadrados, $0,15-0,2 \times$ ca. $0,2 \mathrm{~cm}$, ápice obtuso, estigma arredondado, com ganchos na base; antera 1, cor amarela intensa.

Ocorre no Nordeste, Centro-oeste e Sudeste do Brasil (Bastos 2014). E9, G7: cerrado. Floresce de maio a fevereiro.

Material examinado - Alagoinhas, $3 \mathrm{~km}$ a oeste da sede do município, 1209'37'S, 38²6'17'W, 170-220 m s.n.m., 29 jan. 2000 (fl.), F. França 3221 (CEPEC, HUEFS); Vitória da Conquista, $14^{\circ} 51^{\prime} 01^{\prime \prime S}, 40^{\circ} 50^{\prime} 59^{\prime \prime}$ W, 880 m s.n.m., out. 1991 (fl.), L.C. Menezes 20 (holótipo UB).

Encyclia osmantha é comumente confundida com E. advena e E. alboxanthina. No entanto, essas espécies apresentam lobo mediano reniforme (a primeira delas) ou arredondado (a segunda). Além disso, em disposição explanada, os lobos laterais do labelo de E. osmantha formam um ângulo $<45^{\circ} \mathrm{em}$ relação ao lobo mediano, enquanto nas demais espécies, os lobos laterais formam um ângulo de cerca de $90^{\circ}$.

12.Encyclia patens Hook., Bot. Mag. 57: pl. 3013. 1830.

= Encyclia odoratissima (Lindl.) Schltr., Orchideen: 210. 1914.

$=$ Encyclia flava (Lind1.) Porto \& Brade, Rodriguésia 1: 246. 1935.

Erva epífita, 26,5-43,8 cm alt. Pseudobulbos cônicos, (4)7,1-8,8 × (1,7) 2-2,5 cm. Folhas 2 ou 3, lanceoladas a oblongas, (19-)21,1-35,0 × 1,0-1,8 cm, ápice agudo. Inflorescência em racemo simples, 6-20 flores; pedúnculo 15,5-25,6 cm compr.; raque 10,8$14,0(17,0-19,0) \mathrm{cm}$ compr. Flores com pedicelo 1,8$3,7 \times 0,2-0,3 \mathrm{~cm}$, sépalas esverdeadas com traços vinosos ou amarelo-esverdeadas, pintalgadas de castanho-vinoso, a dorsal lanceolada, 1,5-1,7 × 0,3-0,5 $\mathrm{cm}$, as laterais lanceoladas, $1,5-1,8 \times$ ca. $0,5 \mathrm{~cm}$, patentes, membranáceas, margem inteira, ápice agudo; pétalas esverdeadas com traços vinosos, ou amareloesverdeadas, pintalgadas de castanho-vinoso, espatuladas, ca. 1,5 $\times 0,5 \mathrm{~cm}$, patentes, membranáceas, margem inteira, ápice agudo, labelo com istmo $0,1-0,2$ $\times 0,15-0,3 \mathrm{~cm}$, lobos laterais brancos, dimidiados, $0,8-$ $0,9 \times 0,3-0,4 \mathrm{~cm}$, ângulo ca. $45^{\circ}$ em relação ao lobo mediano (no labelo explanado), não sobrepostos ao lobo mediano, ápice obtuso, lobo mediano branco com poucos traços róseos, orbicular ou cordado, $0,6-0,8 \times$ $0,7-0,9 \mathrm{~cm}$, conduplicado, margem inteira, ápice uncinado, calo com ápice agudo; coluna clavada, 0,7-1 $\times \quad 0,3-0,5 \mathrm{~cm}$, dentes laterais do clinândrio corniformes, ápice premorso, braços da coluna quadrados, $0,15-0,2 \times$ ca. $0,1 \mathrm{~cm}$, ápice obtuso, estigma arredondado, com ganchos na base; antera(s) 1 ou 3 , cor amarela intensa.

\section{Chave para as variedades}

1. Antera 1 12a. E. patens var. patens

1'. Anteras 3 12b. E. patens var. serroniana

\section{2a. Encyclia patens Hook. var. patens}

Figura 7 e 8S-Y.

Amplamente distribuída no Sudeste, ocorre também no Nordeste e Sul do Brasil (Bastos 2014). I7: mata ciliar. Em cultivo, floresce todos os meses do ano.

Material examinado - Arataca, Parque Nacional da Serra das Lontras, na trilha para a Serra Peito de Moça, 16022'09"S, $40^{\circ} 02^{\prime} 26^{\prime} \mathrm{W}, 659$ m s.n.m., set. 2012 (fl.), C.A. Bastos 340 (HUEFS).

12b. Encyclia patens var. serroniana (Barb.Rodr.) Romanini \& F.Barros, Fl. Fanerog. Ilha Cardoso 12: 102.2007.

Figuras 9 e $10 \mathrm{~A}-\mathrm{H}$.

Endêmica do Brasil, ocorre nas Regiões Sudeste, Sul e Nordeste (Bastos 2014). D6, E6: mata de grotão. Floresce de junho a novembro.

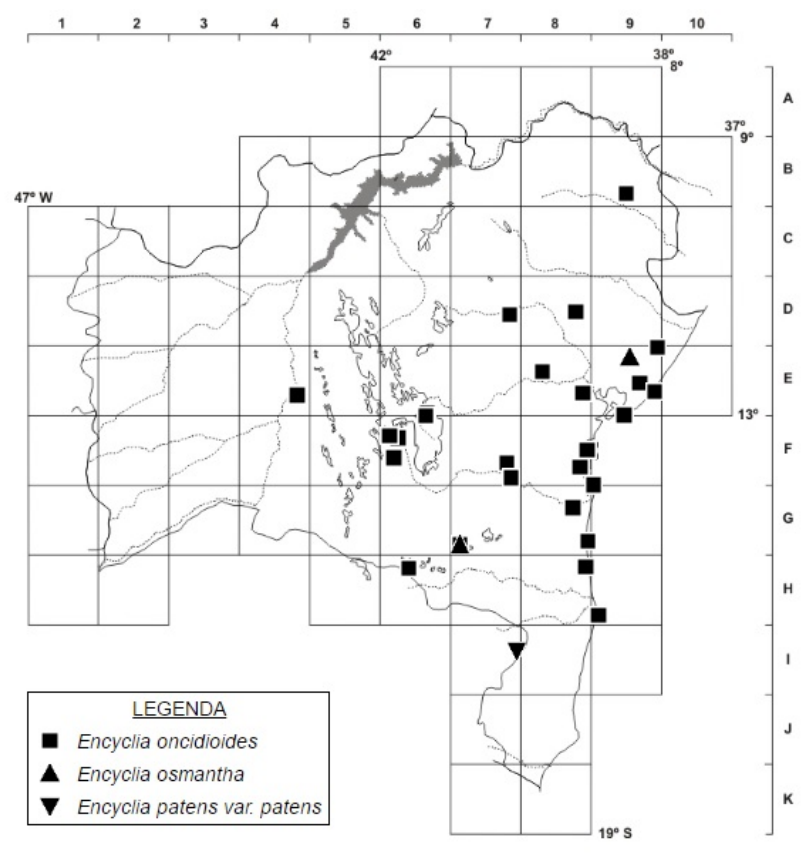

Figura 7. Mapa de distribuição geográfica na Bahia: Encyclia oncidioides, E. osmantha e E. patens var. patens. 


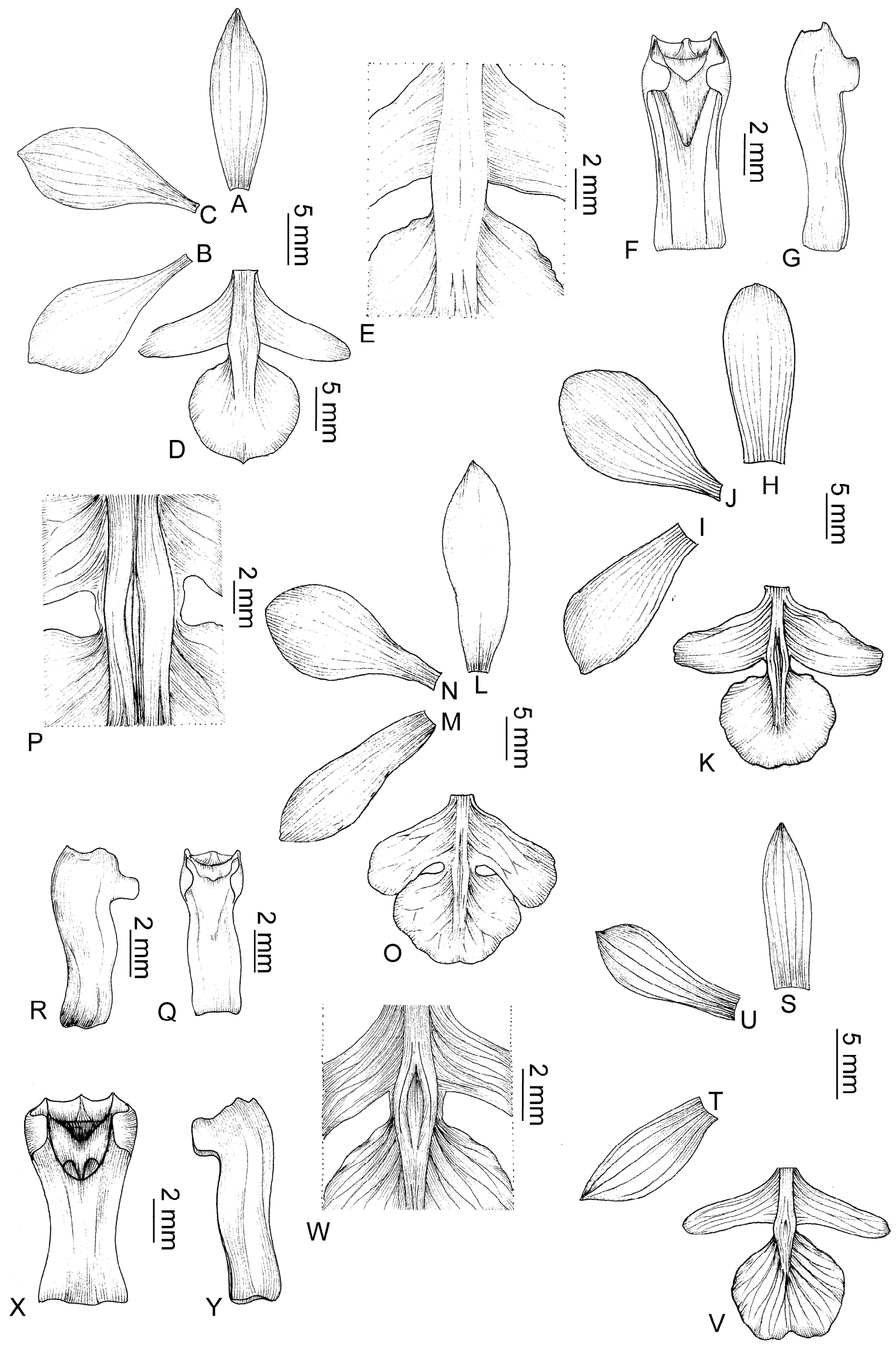

Figura 8. A-K. Encyclia oncidioides: A- sépala dorsal; B- sépala lateral; C- pétala; D- labelo; E- detalhe do calo do labelo; F- coluna, vista ventral; G- coluna, vista lateral (van den Berg 1059); H- variação da sépala dorsal; I- variação da sépala lateral; J- variação da pétala; K- variação do labelo (Hatschbach et al. 68552). L-R. E. osmantha: L- sépala dorsal; M- sépala lateral; N- pétala; O- labelo; P- detalhe do calo do labelo; Q- coluna, vista ventral; R- coluna, vista lateral (França 3221). S-Y. E. patens var. patens: S- sépala dorsal; T- sépala lateral; U- pétala; V- labelo; W- detalhe do calo do labelo; X- coluna, vista ventral; Y- coluna, vista lateral (Bastos 340). 
Material selecionado - Morro do Chapéu, Morrão,

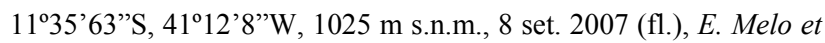
al. 5071 (HUEFS); Mucugê, Gerais do Guiné, 12\%45'9'S, 41³0'29"W, 1400 m s.n.m., 10 nov. 2008 (f1.), C. Azevedo \& V.A.O. Dittrich 347 (HUEFS).

Encyclia patens var. patens caracteriza-se por apresentar o labelo com o lobo mediano orbicular e a coluna com apenas uma antera (monandra), diferente da E. patens var. serroniana que possui três anteras. Segundo Barros (1983), a presença de três anteras pode resultar em autopolinização, formando populações autógamas, isoladas das populações monandras, que são alógamas. Além disso, E. patens var. patens apresenta flores claras, esverdeadas com traços vinosos e perfumadas, enquanto E. patens var. serroniana apresenta flores amarelo-esverdeadas, pintalgadas de castanho-vinoso, e é desprovida de qualquer perfume (Romanini \& Barros 2007). Encyclia patens var. serroniana pode ser facilmente identificada nos herbários por ter o ovário com superfície áspera, além de ser menor

\section{Encyclia unaensis Fowlie, Orchid Digest 55(1): 27} 1991.

Figuras 9 e 10I-P.

Erva epífita, ca. $18,5 \mathrm{~cm}$ alt. Pseudobulbos ovoides, ca. $1,1 \times 0,5 \mathrm{~cm}$. Folhas 1 ou 2, oblanceoladas a lineares, ca. 17,2 × 0,6 cm, ápice agudo. Inflorescência em racemo simples, ca. 3 flores; pedúnculo ca. $19 \mathrm{~cm}$ compr.; raque ca. 4,4 cm compr. Flores com pedicelo $1,8-2,2 \times 0,1-0,2 \mathrm{~cm}$, sépalas amarelo-acastanhadas, a dorsal lanceolada, ca. 1,7 $\times$ $0,5 \mathrm{~cm}$, as laterais lanceoladas, ca. $1,5 \times 0,5 \mathrm{~cm}$, pendentes, membranáceas, margem inteira, ápice agudo; pétalas amarelo-acastanhadas, espatuladas, ca. $1,6 \times 0,5 \mathrm{~cm}$, pendentes, membranáceas, margem inteira a suavemente serreada, ápice agudo, labelo com istmo ca. $0,1 \times 0,2-0,3 \mathrm{~cm}$, lobos laterais brancos, dimidiados, $0,7-0,8 \times 0,4 \mathrm{~cm}$, ângulo ca. $45^{\circ}$ em relação ao lobo mediano (no labelo explanado), não sobrepostos ao lobo mediano, ápice obtuso, lobo mediano branco densamente tracejado de rosa, orbicular, $0,6-0,7 \times 0,7-0,8 \mathrm{~cm}$, conduplicado, margem ondulada, ápice emarginado, calo com ápice agudo; coluna dolabriforme, ca. 0,9 × 0,2-0,4 cm, dentes laterais do clinândrio triangulares, ápice agudo, braços da coluna ovais a quadrados, ca. $0,1 \times$ $0,2 \mathrm{~cm}$, ápice obtuso, estigma triangular, com ganchos na base; antera 1, cor amarela intensa, ca. $0,2 \times 0,2$ $\mathrm{cm}$.

Endêmica da Bahia (Bastos 2014). D7, E8, F8, G8, H8, I8: Mata Atlântica. Floresce entre agosto e fevereiro.

Material selecionado - Almadina, Serra do Corcovado, 14²' '11's, 39³6’08'W, 470-850 m s.n.m., 17 jan. 2007 (fl.), A.P. Fontana et al. 2626 (CEPEC); Arataca, Serra Peito de Moça, 1509'39”'S, 39²0’37’W, 500-988 m s.n.m., 20 jan. 2007 (fl.), A.P. Fontana et al. 2659 (CEPEC); Itacaré, estrada Itacaré-

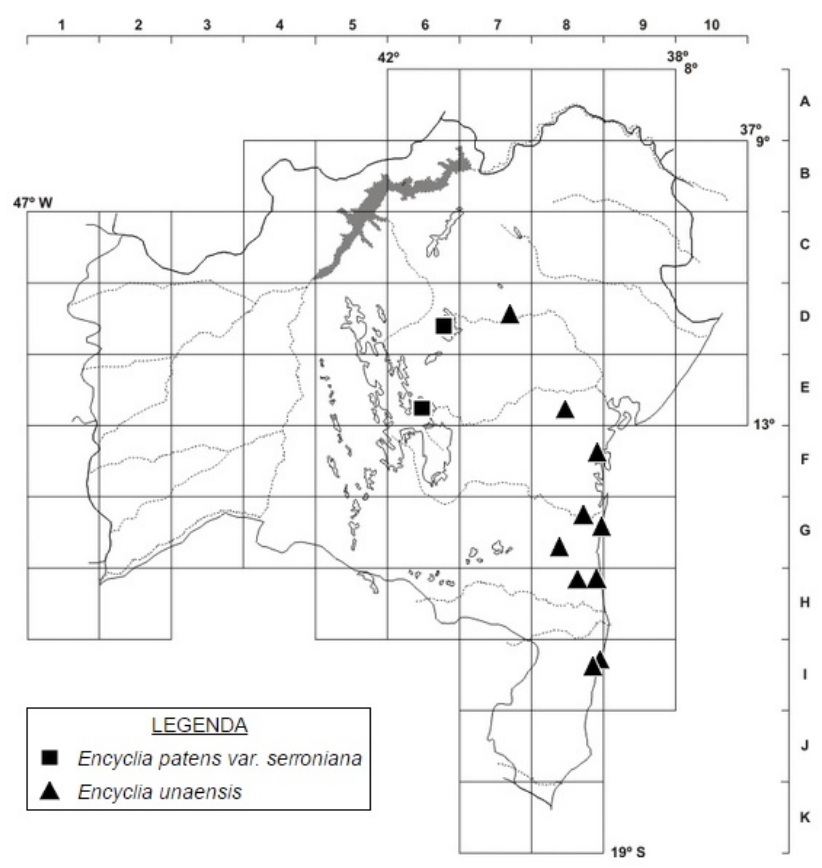

Figura 9. Mapa de distribuição geográfica na Bahia: Encyclia patens var. serroniana e E. unanesis.

Taboquinhas, 14¹5'00”'S, 39¹6’12”W, 14 dez. 1992 (fl.), A. Amorim et al. 934 (CEPEC); Porto Seguro, próximo à Estação Ecológica do Pau-Brasil, 16²2'60'S, 3907'59'W, 25 jan. 1980 (fl.), F. Barros 14 (SP); Santa Cruz Cabrália, Reserva Biológica Pau-Brasil, 166'60"S, 3901'59'W, 24 jan. 1972 (fl.), $A$. Eupunino 165 (CEPEC); Santa Teresinha, Serra da Jiboia, 1246'13"S, 39³1'12"W, 10 jan. 2006 (fl.), C. van den Berg 1559 (HUEFS); Serrolândia, $11^{\circ} 26^{\prime}$ S, $40^{\circ} 17^{\prime}$ W, 20 ago. 1980 (fl.), G.C. Pereira Pinto 18/80 (HRB); Una, Reserva Biológica do Mico-Leão, 1509'S, 3905'W, 1 dez. 1997 (fl.), A.M. Amorim 2105 (CEPEC); Uruçuca, estrada Uruçuca-Itacaré, 14²5'S, 3901'W, 5 fev. 1993 (fl.), W. Thomas et al. 9749 (CEPEC); Valença, torre na BR-101, 13²2'15”'S, 3904'21'”, 11 dez. 2009 (fl.), C. van den Berg 1957 (HUEFS).

Encyclia unaensis apresenta flores com labelo esbranquiçado, com lobo mediano orbicular e fortemente tracejado de rosa. A morfologia floral aliada à vegetativa, com folhas oblanceoladas a lineares e arroxeada, diferencia a espécie das demais do gênero.

\section{Agradecimentos}

Os autores agradecem ao Conselho Nacional de Desenvolvimento Científico e Tecnológico (CNPq), pela concessão da bolsa de doutorado; às pessoas vinculadas ao HUEFS, pela colaboração; aos herbários ALCB, AMO, BM, CEN, CEPEC, CESJ, ESA, G, GENT, GUA, HB, HEPH, HRB, HRCB, HTO, HUEFS, IBGE, IAC, IAN, INPA, K, LP, MBM, MBML, MG, R, RB, SP, SPF, SPSF, UB, UC, UFG, UEC, UPCB, UPRRP, VEM, VIC, VIES e W, pela assistência na análise dos materiais; e à Carla de Lima, pelas ilustrações. 


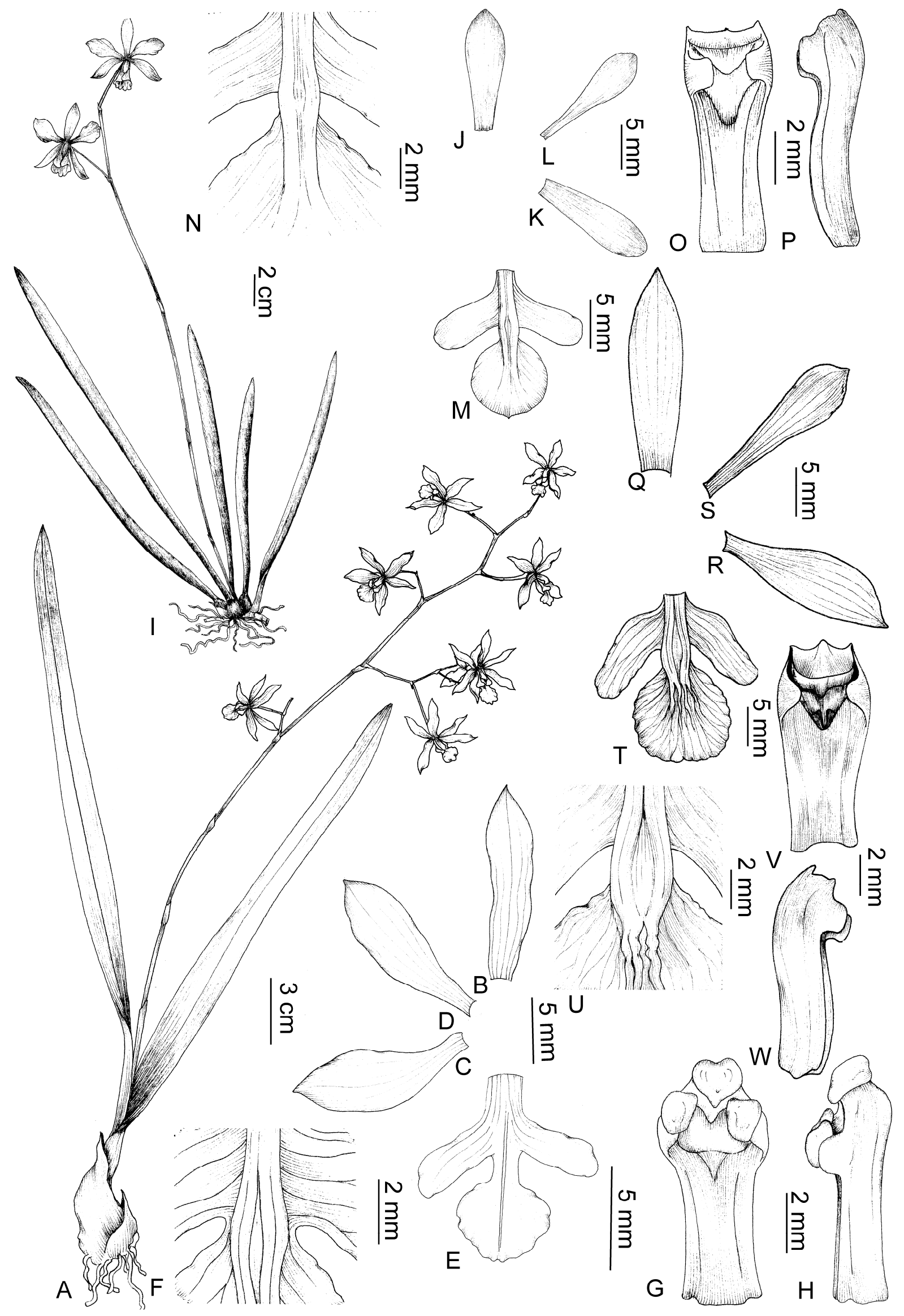

Figura 10. A-H. Encyclia patens var. serroniana: A- hábito; B- sépala dorsal; C- sépala lateral; D- pétala; E- labelo; F- detalhe do calo do labelo; G- coluna, vista ventral; H- coluna, vista lateral (Melo 5071). I-P. E. unaensis: I- hábito; J- sépala dorsal; K- sépala lateral; L- pétala; M- labelo; N- detalhe do calo do labelo; O- coluna, vista ventral; P- coluna, vista lateral (Azevedo 4). 


\section{REFERÊNCIAS}

Almeida, P.R.M. 2009. Associação Micorrízica e Estudo da Variabilidade Intra e Interespecífica em Populações de Encyclia dichroma (Lindl.) Schltr. e E. ghillanyi Pabst (Orchidaceae). Dissertação de Mestrado. Universidade Estadual de Feira de Santana.

Barros, F. 1983. Flora Fanerogâmica da Reserva do Parque Estadual das Fontes do Ipiranga: Orchidaceae. Hoehnea 10: 74-124.

Barros, F.; Vinhos, F.; Rodrigues, V.T.; Barberena, F.F.V.A.; Fraga, C.N.; Pessoa, E.M.; Forster, W. \& Menini Neto, L. 2013. Orchidaceae. In: R.C. Forzza, J.F.A. Baumgratz, C.E.M Bicudo, A.A. Carvalho Jr., A. Costa, D.P. Costa, M. Hopkins, P.M. Leitman, L.G. Lohmann, L.C. Maia, G. Martinelli, M. Menezes, M.P. Morim, M.A.N. Coelho, A.L. Peixoto, J.R. Pirani, J. Prado, L.P. Queiroz, V.C. Souza, J.R. Stehmann, L.S. Sylvestre, B.M.T. Walter \& D. Zappi (eds), Lista de Espécies da Flora do Brasil. Jardim Botânico do Rio de Janeiro, disponível em http://floradobrasil.jbrj.gov.br/2010/FB011518; acessado em 20 set. 2013.

Bastos, C.A. 2014. Filogenia do Gênero Encyclia Hook. (Orchidaceae - Laeliinae) e Revisão Taxonômica das Espécies Brasileiras. Tese de Doutorado. Universidade Estadual de Feira de Santana.

Bastos, C.A. \& van den Berg, C. 2012. Flora da Bahia: Catasetum (Orchidaceae). Sitientibus série Ciências Biológicas 12: 83-89.

Bastos, C.A.; van den Berg, C. \& Meneguzzo, T.E.C. 2012. Encyclia fimbriata (Orchidaceae: Laeliinae), a new largeflowered species from Bahia, Brazil. Phytotaxa 40: 26-40.

Bastos, C.A.; Meneguzzo, T.E.C. \& van den Berg, C. 2015. Taxonomic notes on Brazilian Encyclia (Orchidaceae: Laeliinae). Phytotaxa 218(1): 77-83.

Campacci, M.A. 2003. Encyclia. Coletânea de Orquídeas Brasileiras 1: 1-32.

Castro Neto, V.P. \& Bohnke, E. 2010. Uma nova Encyclia para o estado da Bahia. Boletim CAOB 79: 45-49.

Castro Neto, V.P. \& Campacci, M.A. (eds). 2000. Encyclia fowliei Duveen. Icones Orchidacearum Brasiliensis 1: t. 20.

Ferreira, A.B.G. (1996) Encyclia xerophytica: a verdade sobre sua origem. Orquidário 10(4): 113.
Fowlie, J.A. \& Duveen, D. 1992. A Contribution to an understanding of the genus Encyclia as it occurs in the Brasilian shield and its river tributaries. Orchid Digest 56: 171-206.

Gerard, F. 1848. Epidendrum roseum. Portefeuille des Horticulteurs 2: 266-267.

Govaerts, R.; Dransfield, J.; Zona, S.F.; Hodel, D.R. \& Henderson, A. 2013. World Checklist of Orchidaceae. Royal Botanic Gardens, Kew. Disponível em http://apps.kew.org/ wcsp/; acessado em 20 set 2013.

McNeill, J.; Barrie, F.R.; Buck, W.R.; Demoulin, V.; Greuter, W.; Hawksworth, D.L.; Herendeen, P.S.; Knapp, S.; Marhold, K.; Prado, J.; Prud'homme van Reine, W.F.; Smith, G.F. Wiersema, J.H. \& Turland, N.J. 2012. International Code of Nomenclature for algae, fungi and plants (Melbourne Code). Regnum Vegetabile 154: 1-232.

Monteiro, S.H.N.; Santos, L.A.S. \& Carregosa, T. 2012. Expanding the distribution of Encyclia alboxanthina Fowlie (Orchidaceae, Laeliinae). Revista Brasileira de Biociências 10(2): 248-250.

Pabst, G.F.J. 1976. Additamenta ad Orchideologiam Brasiliensem 22. Bradea 2(14): 79-90.

Reichenbach Filho, H.G. 1854. Miscellanées: 697. Repertoire de Botanique. Flore des Serres 9: 98.

Romanini, R.P. \& Barros, F. 2007. Orchidaceae. In: M.M.F.R. Melo, F. Barros, S.A.C. Chiea, M. Kirizawa, S.L. JungMendaçolli \& M.G.L. Wanderley (eds), Flora Fanerogâmica da Ilha do Cardoso. Vol. 12. Instituto de Botânica, São Paulo, p. 29275.

Toscano de Brito, A.L.V. \& Cribb, P. 2005. Orquídeas da Chapada Diamantina. Nova Fronteira, São Paulo.

Van den Berg, C. \& Carnevali, G. 2005. Encyclia. In: A.M. Pridgeon, P.J. Cribb, M.W. Chase \& F.N. Rasmussen (eds), Genera Orchidacearum. Vol. 4. Oxford University Press, New York, p. 232-236.

Withner, C.L. 1998. The Cattleyas and Their Relatives 5: Brassavola, Encyclia, and other genera of México and Central América. Timer Press, Portland.

Withner, C.L. 2000. The Cattleyas and Their Relatives 6: The South American Encyclia species. Timer Press, Portland.

\title{
LISTA DE EXSICATAS
}

\begin{abstract}
Abendroth, A. P-63 (12a); Almeida, P. 1, 2 (9), 3 (6), 4 (9), 5 (6); Alves, M. 58 (2); Amorim, A. 934 (13), 1318 (6), 2105 (13); Angeli, C. s.n. HB 57333 (12a); Araújo, D. 738 (12a), 5310 (10), 7911 (12a), 9050 (10);Araújo, J. 125 (6); Arkle, J. s.n. K 878409 (6); Arple, W. s.n. K 878387 (10); Assis, J. s.n. ALCB 52004 (9); Athayde, P. s.n. RB 109022 (6); Azevedo, C. 4 (13), 10 (9), 159 (2), 347 (12b); Azevedo, M. 307 , 405 (11); Barros, F. 14 (13), 20 (5), 736 (12a), 2444 (2), s.n. SP 342971 (10); Bastos, C. 53 (2), 64 (3), 65,66 (10), 70,89 (2), 156 (10), 176 (3), 252 (2), 286 (11), 289, 296 (3), 303 (5), 307 (8), 318, 319 (3), 322 (8), 340 (12a); Batista, J. 207,323 (11), 1586 (2); Bautista, H. 70, 284, 1341(2); Belém, R. 833, 834 (5), 2033 (10), 2426, 2458 (6), 3421 (10); Berger, M. s.n. MBML 21717 (12a); Bernacci, L. 28427, 28428, 28429 (12a); Bianchetti, L. 954, 1178 (11); Bicalho, H. s.n. SP 168417 (10), SP 342967 (11); Blanchet 1743 (10); Blanchet, J. 1520 (6); Blumenschein, A. s.n. ESA - ficha 8083, 22458 (2); Bohnke, E. s.n. SP 339145, SP 341858 (4); Bohrer, C. 1 (10); Bonnet, A. s.n. UPCB 65182 (12a); Borba, E. 2067 (2), 2114 (12a); Borges, M. 248 (12a); Borvie, J. s.n. BM 47513 (12a); Brade, A. 7505, 16814 , s.n. HB 8326, HB 8327 (12a), HB 8328 (10), RB 199931 (12b); Bradford s.n. K 583877 (5); Braga, J. 1888 (1), 2797 (12a); Braga, P. 1674 (12a); Braz, H. 1463 (12a); Breier, T. 360 (12b), 1271 (10); Brian, M. s.n. K 583876 (5); Brick, S. s.n. HB (12b); Brieger s.n. ESA ficha 19745 (12a); Brien, M.J.D. s.n. K (8); Brito, J. 111 (2); Brosolin, A. 328 (12b); Burchell 998, 2933 (12a); Burle-Marx, R. s.n. HB 69255 , HB 69273 (10); Campos, M. s.n. ALCB 21876 (6); Carauta, J. 4511 (12a); Carlinda s.n. ALCB 15223 (6); Carneiro, E. 484 (2); Carneiro, J. 345 (11), 638 (1); Carriz, B. s.n. HUEFS 161279, RB 57458 (12a), RB 46250 (3), RB 199928 (12a); Carvalho, A. 751 (10), 1094 (6), 1279 (5), 6791 (10), 7053 (2); Carvalho, D. 11 (10); Carvalho, M. 1 (6); Castellanos, A. s.n. R 4467 (12a); Castro Neto, V.
\end{abstract}


17199 (3), s.n. HB 70515 (10); Castro, R. 538 (12a); Cattan, G. 53 (12a); Celina s.n. ESA ficha - 22757 (11), ESA ficha - 26350 (10); Conceição, A. 486 (2); Coradin, L. 4481 (2);Corvan, M. s.n. K 878389 (10); Costa, L. 407 (10); Costa, S. 357 (2);Cotrim, A. 348 (2); Dalla, J. s.n. MBML 38039 (12a); Davidse, G. 11829 (9); Dechioni, P. 73 (12a); Delforge, R. s.n. RB 199930 (10); Demuner, V. 1863 (5); Desvaux, E. s.n. P 410729, P 410749 (12a); Dittrich, V. 1586 (11); Dorclano 17 (2); Duarte, A. 9195 (2), 10626 (9), 11242 (11); Duarte, C. 63 (12a); Duch, A. s.n. HB 57098 (10); Dungs s.n. HB 57248 (10); Dusen, P. 15210 (12a), 16124 (10); Edmundo, F. s.n. SP 330902 (13); Emmerich, M. s.n. HB 41116 (12a); Emydio, L. 1522 (12a), 2485 (13); Eupunino, A. 165 (13); F.D.R. 89 B10 (2); Félix, L. s.n. HUEFS 158823, HST 9119 (10); Ferreira, A. 40, s.n. HB 66725 (10), P 410731 (12a); Ferreira, M. 667 (2); Ferreira, V. 4075 (10); Fevereiro, V. 66 (10); Folli, D. 2653 (10); Fontana, A. 30, 217 (3); 296, 522 (5), 607, 693, 1670 (12a), 2626, 2659 (13), 2830 (1), 2831, 3020 (5); Forster, W. 497 (12a), 818 (11); Fraga, C. 766 (10); França, F. 1322, 1518 (9), 2441 (2), 3221 (11), 5177 (9), 5343 , 5377 (2); Franco Filho, A. 1 (10); Frazão, A. s.n. RB 14836 (12a); Freire, C. s.n. R 36314 (12a); Furlan, A. 276,434 (2), 806 (10); G.F.M. 2 (11); Galsiou, A. 18514 (12a); Ganev, W. 1235, 2363 (10), 2688, s.n. HUEFS 13707 (2); Gardner 5204/3 (12a); Garston s.n. K 878411 (6); Gatti, G. 522 (12a); Geraldo s.n. ESA - ficha 14654 (12b); Gevieski, A. 75 (10); Ghillany, A. 007/74 (9); Ghillany, B. 74 (9), 471 (2), s.n. HB 63230 (9); Giacometti, D. 882 (1); Ginzbarg, S. 844 (9); Giongo, C. 84 (12a); Giordano, L. 1228 (6); Giulietti, A. 7096 (2); Glaziou, A. 15658, 15660 (10); 18514 (12a); Góes, O. 1100 (12a); Golnago, E. 394 (10); Gomes, C. s.n. RB 29810 (12a); Gomes, F. 541 (2); Gomes, V. 12, 2681 (12a); Grande, D. s.n. SP 162661 (10); Guedes, M. 614 (6), 1489 (2), 3223-B (6), 5512 (2), 8961 (6), 11219 (10), 16865, 19262 (2), s.n. ALCB 15801 (10), ALCB 25848, MBM 249774 (6); Guimarães, A. 1258, s.n. RB 46201 (1); Gurgel, D. 14863 (10), 14906 (9), 14977 (6), s.n. ESA - ficha 14859 (9); Haas 402 (11); Hage, J. 1961 (9); Handro, O. 254 (12a); Harley, R. 7016, 14062, 14263 , 15962, 16853, 18767 (2), 19426 (9), 20914 (2), 24100 (6), 27834 (2), 28225 (9), 50327 (2); Hatschbach, G. 12080 (11), 13383 (10), 16668 (12a), 23369 (10), 39658, 47504, 50095 (2), 66526 (12a), 68552 (10), 69406 (11), 75802 (9), 90095 (2); Hening, E. s.n. HB 3078 (3); Heringer, E. 582 (12a), 3352 (11), 5073 (10), 5396 (11), 8453-647, 9620, 9691, s.n. SPF 84013-1 (1); Hoehne, F. 3419 (12a), 17473 (12b), 20559, 34715 (10); s.n. HUEFS 185650, SP 5842 (12a), SP 8141 (10), s.n. SP 35063 (1), s.n. SPF 81937 (12a); Hoehnes, W. s.n. RB 199926 (6); Holmes, C. s.n. SP 30555; Hosman, F. s.n. K 878410 (6); Irwin, H. 32341 (2); Jacaraby 7 (12a); Jaci, X. 43 (12a); Jardim, J. 751 (2), 4138 (10); Jenisch s.n. W 24649, W 24650, K 293834 (9); Jesus, N. 1358 (2); Juchum, F. 69 (10); Junqueira, M. 150 (2); Kauskii s.n. HEPH 213675 (5); Katusky, R. 152 (5), 641 (12a), s.n. HB 75236 (1), HB 75237 (10), s.n. HB (12a); Kepe 1257 (6); Kersten, R. 399 (12a); Klein, R. 7450 (12b), 7862 (12b); Koch, I. 662 (2); Kollmann, L. 1488 (1), 2921, 3041, 3691 (5), 4045 (10), 4789 (12a), 9344 (3), 11907 (7), s.n. MBML 3681 (12a); Kral, R. 75633 (2); Krause, V. s.n. MBML 1356 (5); Kundegraber, H. s.n. SP 247777 (1), SP 333602 (3); Landim, M. 1087 (10); Lannders, M. s.n. K 878030 (12a); Laurence, T. s.n. K 878025 (12a); Leão, N. 4D (12a); Leining, M. 68 (10), 142 (12a); Leitão, C. s.n. VIC 31026 (2); Leitão, H. 10388 (9); Leitão, R. s.n. SP 398307 (3); Leite, K. 252 (9); Lemos, R. 4379 (10); Leoni, L. 5 (12a); Lewis, G. 946 (2); Lima, C. 51 (9); Lima, D. s.n. HB 40979 (10), HB 40981 (10); Lima, H. 4624 (1); Linot 1688 (12a); Löefgren, A. s.n. RB 256834 (12a); Lombardi, J. 6985 (10); Lopes, W. 609 (5); Lordêlo, R. $57-46$ (10), $58-27$ (9); Loureiro, D. 750 (10); Luederwaldt, H. s.n. HB 19620; Macêdo s.n. HUEFS 176106; Machado, E. s.n. HUEFS 165185, HB 20008 (1); Magalhães, M. 51319 (12a), s.n. HB 20895 (1); Magnago, L. 1260 (5); Marquete, R. 1922 (12a); Martinelli, G. 325 (12b), 2553 (12a), 5156 (2), 5440 (2), 6646 (9); Martins, A. 5654 (2); Matos, E. 623 (10); Mazzini, E. 4 (12a), s.n. SP 39050 (10); Melo, A. EM-42A (11), s.n. HB 63153 (5); Mello, A. s.n. HB 63005 (5); Melo, E. 1102 (9), 1333 (2), 1361 (9), 1663 (2), 5071 (12b); Melo, M. 1 (4); Mendonça, R. 4996 (11); Meneguzzo, T. 466 (13), 473 (3), 517 (4), 520, 521 (1), 523 (4), 567 (3); Menezes, L. 20 (11), UB 28 (3); Menini Neto, L. 113 , 165 (12a); Milanezi, M. s.n. VIES 3213 (12a); Miranda, Z. 2 (11); Mirens, J. 3545, 4245 (12a); Monteiro, E. 6486 (6), 6487 (2); Moraes, A. 100 (10); Moraes, J. 1503 (10); Moraes, M. s.n. RB 368926 (12a); Mori, S. 9942, 11085 (9), 11296 (10), 13347 (2); Moses, T. 15 (10); Moura, C. 101 (12a); Muller, F. s.n. K 583897 (12a); Muus, R. s.n. SP 30797 (10); Nascimento, C. 52 (6); Nascimento, J. 201 (2); Neves, S. 180 (2); Noblick, L. 1673 (6), 2011 (9), 2883 (2), 3091 (9), 4422 (10), 4478(6); Nobrega, M. 504 A, 940, 986A (11); Nunes, S. 201 (9); Nursery, C. s.n. K 878386 (10); Occhioni, P. 73 (12a); Oliveira, A. s.n. ESA - ficha 17367 (9), 17375 (10), 17377, 17378 (9), 17408 (10), 18038 (3), 18087, 18090 (10), 18135, 18136, 18143, 18586, 18783, 18805, 18932 (13); Oliveira, A. 266 (2); Oliveira, C. 2293 (12a); Ostermeyer, R. s.n. SP 24102 (5); Pabst, G. 265 (10), 5187, s.n. HB 424, HB 481, HB 681, HB 1090 (12a); Pacheco, R. 249 (11); Pansarin, E. 199, 849, 1071 (12a); Paula-Souza, J. 4804 (2); Pelizzaro, K. 23, 56 (11); Pereira Neto, M. 361 (11); Pereira, E. 2247 (12a); Pereira, L. E2 (11); Pereira-Silva, G. 8419 (2); Peres Jr., A. 12 (11); Pickel, B. 898 (1); Pinel s.n. P 410746 (12a); Pinto, G. 18 (3), 115 (9), 18/80 (13), s.n. HRB 31060, ALCB 477 (2); Pinto, R. s.n. ALCB 477 (2), HB 70298 (10);Pires, J. 5117, 9639 (11); Plowman, T. 12765 (6); Polo, L. 776 (12a); Popovkin, A. 504 (10), 621 (4); Porto, C. 304 (12a); Proença, C. 3623 (11); Queiroz, E. 221 (9), 1130 (10), 2776 (2), 4579 (9); Queiroz, L. 464 (10), 500, 513 (6), 1261 (2), 1387 (10), 1410 (6), 5585 (2), 9380 (9), 9737 (2), 12217 (9), 12994 (10); Quesnel s.n. K 293885 (6), s.n. P 411538 (12a); Rapini, A. 941 (2); Regnell, A. 1151 (12a); Reis, C. 45 (10); Reitz, R. 1204 (12a), 4261 (10); Ribeiro, A. 84 (6); Ribeiro, J. 543 (10), 574, 582 (12a); Ribeiro, W. s.n. SP 329737 (12a); Riedel, L. 9 (12a); Rigueira, D. s.n. ALCB 67949, MBM 305942, ALCB 69064, CEPEC 107430 (10); Riviére, A. s.n. P 410728 (12a); Robr. 2028 (12a); Rodrigues Jr., C. 1547 (2); Rodrigues, V. 59, 60 (12a); 69 (12b); Rodrigues-da-Silva, R. 627 (11); Rohr 2045 (10); Romanini, R. 211 (12a), 233 , 240,241 (10), 242 (12a), 304 (12b), 305 (12b), 307 (12b); Roque, N. 1080, 1300, 1531 (2); Rosa, M. s.n. R 36503 (12a); Rossini, J. 401 (12a); Ruhr, J. 560 (12a), s.n. HB 748 (12b); Salib, J. HB 19439 (12a); Salimena, F. 194 (12a); Salles, A. 2396 (10), 2416 (2), 3828 (3), 4197, 4235 (12a); Sampaio, A. 4571 (12a); Sanden, C. s.n. K 878412 (6); Sander, F. s.n. K 294031 (1), K 878024, K 878031 (12a), K 878393 (10), K 879265 (12a); Santana, D. 649 (2); Santana, I. 58 (12a); 68 (12a); Santos 5 (12a); Santos, A. 48 (9), 348 (2); 1944 (11); 2086 (11); 2450 (9); Santos, E. 299 (9); Santos, J. 173 (10); Santos, L. 7 , 59 (2), s.n. ASE 19683 (6); Satemau, W. 5491 (6); Schimidt, M. s.n. SP 52151 (1); Seidel, A. 887 (12b), 889 (12a), 901 (1), 1038 (12b); 1144 (12a); 1205 (12b), 1381 (2); Sesani, J. s.n. K 879008 (10); Shimoya, C. s.n. VIC 5148 (12a); Shwancke, P. 1359 (12a); Silva, E. s.n. SP 363183 (4); Silva, L. 3826 (6); Silva, R. 7620 (2); Silva-Castro, M. 1034 (2), 1076 (3); Silveira, F. 7409 (6), s.n. RB 7409 (6); Singer, R. s.n. UEC 140084 (12a), UEC 140085 (11); Smidt, E. 186 (9); Soeiro, 
R. 87 (6); Souza, E. 63, 88 (10); Souza, W. 1029 (12b); Spannagel, C. 20, R 16716 (12a); Sratori, M. 672 (12a); Stancik, J. 41 (12b); Stannard, B. 52746 (2); Sucre, D. 944, 9154 (12a); Thomas, W. 9749 (13); 12651 (10); 12980 (2); 13220 (12a); 14604 (7); Toscano, A. 1827, 2104, s.n. RB 368925 (10); Trindade, R. s.n. ESA ficha - 16159 (12a); Udulutsch, R. 659 (12a); Urben-Filho 251 (12a); Valente, I. 24 (11); van den Berg, C. 185 (12a), 849, 909, 926 (9), 1059 (10), 1414 (11), 1432 (2), 1434 (10), 1559 (13), 1577 (4), 1764 (1), 1957,1963 (13), 1970 (9), 1972 (4), 2157 (10), 2162 (12b); Vasconcellos, J. 356 (10); Veiht 85 (12a); Veitch 73 (6); Vervloet, R. 9 (12a), 787 (12b), 2591 (5), 2933 (10); Viana, B. 131 (6);Vianna, M. 1444 (9), 1981 (12a); Vidal, J. II-235 (12a); Vieira, C. 337 (12a); Vieira, T. $59,67,93$ (2); Vienna, M. 533 (12a); Warras, E. 334 (10); Wavra, H. 539 (10); Weathers, J. s.n. BM 99233 (6); Walter, B. 4477 (11); Welter, F. s.n. HB 7631 (10); Welter, N. s.n. HB (12a); Wettstein s.n. W 12044 (12a); Windishi, R. 529 (9); Zappi, L. 32 (5); Zaslawski, W. s.n. SP 399305 (3); Zoéga, F. 27857 (10); s.c. 8257 RB 266978 (10), BM 74198 (6), BM 99216, ESA ficha - 8778 (10), ESA ficha - 31310 (12b), HB 1210 (12a), HB 1980 (9), HB 10650 (10), HB 19875, HB 63374 (11), HB 66456 (12a), HB 71168 (3), HB 78538 (12a), K 79666 (10), K 293642 (6), K 583874, K 583875, K 583878, K 583879 (5); K 583880 (1), K 583895 (12a), K 583896 (12b), K 878029 (12a), K 878382 , K 878385, K 878388, K 878390, K 878391, K 878392 (10), K 878408 (6), K 879009 (9), K s.n. herbário Lindl. (12a), P 410683, P 410730 (12a), P 485103 (10), RB 198880 (9), RB 199929, RB 374239 (12a), RB 43790 (10), RB 44198 (5), RB 90526 (12a), W 933, W 961 (10), W 965 (12b), W 966 (12a), W 3313 (1), W 14550 (5), W 30421 (12a), W 46705, W 46830, K (12a). 